\title{
Biocatalysts for the Epoxidation and Hydroxylation of Fatty Acids and Fatty Alcohols
}

\author{
Steffen C. Maurer and Rolf D. Schmid \\ Institute for Technical Biochemistry \\ University of Stuttgart \\ Allmandring 31 \\ D-70569 Stuttgart \\ steffen.maurer@po.uni-stuttgart.de,rolf.d.schmid@rus.uni-stuttgart.de
}

\section{Introduction}

\subsection{Attractiveness of enzymatic oxyfunctionalization of fatty acids and their derivatives}

Whereas most products of the chemical industry are based on petrochemical feedstocks, considerable efforts have been made during the past few decades to use renewable resources as industrial raw materials. Besides polysaccharides and sugars, plant oils and animal fats play an important role in such programmes because of their ready availability (present production is $>100$ million t/a, which could be increased on demand) of which the lion's share is used for nutrition ( $>55$ million t/a), whereas $\sim 15-20$ million t/a are used for the synthesis of polymers, surfactants, emollients, lubricants, bio-diesel, emulsifiers, etc.) [1].

From a chemical point of view, most natural triglycerides offer just two reactive sites, the ester group and the double bonds of unsaturated fatty acids. In fact, the chemistry of fats and oils is largely focused on the ester group which can be hydrolyzed or catalytically reduced, leading to glycerol and fatty acids or fatty alcohols, respectively. Reactions involving the alkyl chain or double bonds of triglycerides, fatty acids, fatty alcohols or their derivatives represent far less than $10 \%$ of today's oleochemistry, with the production of sulfonated fatty alcohols and their derivatives being a major process of this kind. Oxidation reactions at the alkyl or 
alkenyl chains would be highly desirable as they would lead to oleochemicals with new properties, but the methods available today lack selectivity and require harsh conditions. Notable exceptions are the epoxidation of unsaturated plant oils and the synthesis and use of a few hydroxy fatty acids.

State of the art: plant oil epoxidation. The Prileshajev epoxidation (Figure 1 and 2) of unsaturated plant oils (predominantly soybean oil) is used worldwide for the production of more than 200000 t/a of epoxidized soybean oil.

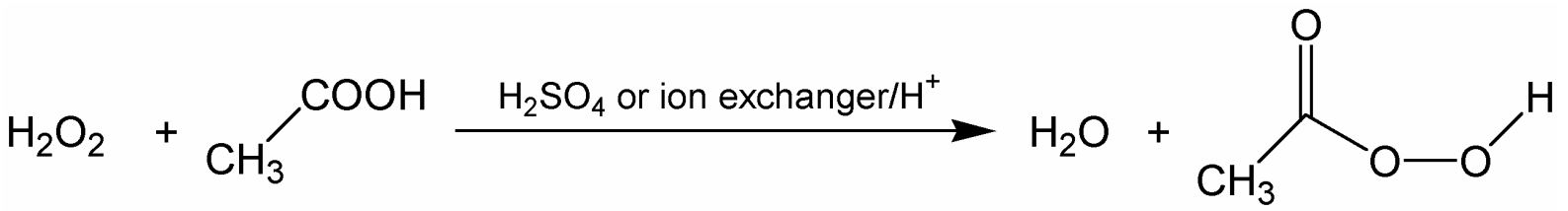

Figure 1: Prileshajev epoxidation: Generation of short-chain peroxy acids

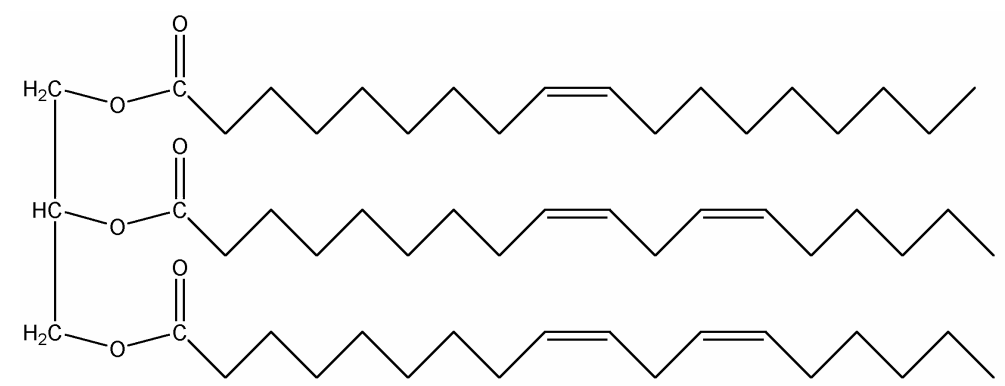

$$
\begin{aligned}
& \mathrm{H}_{2} \mathrm{O}_{2}(70 \%) \\
& \mathrm{CH}_{3} \mathrm{COOH} \\
& \mathrm{H}_{2} \mathrm{SO}_{4} \text { or ion exchanger } / \mathrm{H}^{+} \\
& 60^{\circ} \mathrm{C}, 10-15 \mathrm{~h}
\end{aligned}
$$

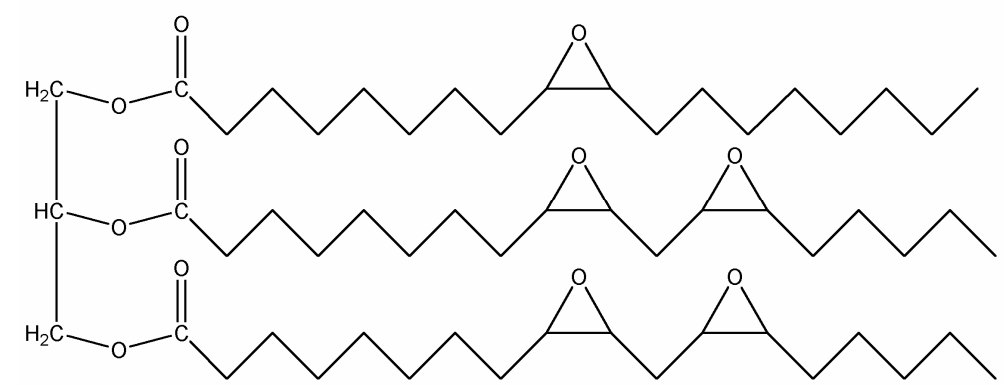

Figure 2: Prileshajev epoxidation: Use of short-chain peroxy acids for epoxidation of unsaturated plant oils

In this reaction, peroxy acids such as peracetic acid are generated from the corresponding acid and hydrogen peroxide in the presence of a strong mineral acid (Figure 1). Due to the potential danger of handling peroxy acids, the intermediate 
peroxy acids are not isolated during large-scale epoxidation of unsaturated triglycerides (Figure 2). There are considerable side reactions via oxirane ring opening, leading to diols, hydroxyesters, estolides and other dimers, which are believed to be catalyzed by the presence of a strong mineral acid. As a result, the selectivity of this process never exceeds $80 \%$ [2]. Furthermore, the presence of a strong acid in an oxidative environment causes corrosion of the equipment. Currently fatty acid epoxides are predominantly used as PVC-plasticizers and -stabilizers, because of their ability to scavenge free $\mathrm{HCl}$ thus slowing down degradation. In addition, epoxidized derivatives of fatty acids are used as reactive dilutants for paints and as intermediates for polyurethane-polyol production. Fatty epoxides also represent valuable raw materials for the production of glues and other surface coatings.

State of the art: hydroxy fatty acids and diacids. At present, the only commercial source of a hydroxy fatty acid is the castor bean (Ricinus communis), a naturally occuring oil crop extensively cultivated in countries like India, Brazil and China. Castor oil contains up to $90 \%$ ricinoleic acid (12R-hydroxy-9Z-octadecenoic acid), which can easily be obtained by hydrolysis of the corresponding triglycerides and is used in a variety of applications such as the manufacture of speciality lubricants, paints and cosmetics [3]. Some other polyhydroxylated fatty acids might be valuable pharmaceuticals or antimicrobial agents. For example 7S,10S-dihydroxy-8Eoctadecenoic acid isolated from Pseudomonas aeruginosa stops growth of the pathogenic yeast Candida albicans, whereas 7S,10S,12R-trihydroxy-8Eoctadecenoic acid also isolated from Pseudomonas aeruginosa exhibits antimicrobial activity and curtails the rice blast fungus (Magnaporthe grisea) [4].

Diacids are important chemical building blocks which are used for the preparation of polyesters, polyamides, adhesives, etc. [5]. On a commercial scale, adipic acid is produced from petrochemical feedstock (through Bayer-Villiger rearrangement of cyclohexanone), and from sebacic acid, which is obtained by ozonolysis of the $\Delta 9$ double bond of erucic acid (13Z-docosenoic acid). $\omega$-Hydroxy fatty acids are produced on a small scale as raw materials or intermediates in the synthesis of $\alpha, \omega$ dicarboxylic acids. 


\section{Oxyfunctionalization of oleochemicals: biotechnological routes - a short}

introduction. Selective biological hydroxylation and epoxidation reactions of fatty acids and fatty alcohols have been shown to be feasible in principle and, as a result, are now a field of active research both in academic and industrial laboratories. At present, three major routes are being explored:

Transgenic oil crops

Fermentation using genetically engineered microorganisms
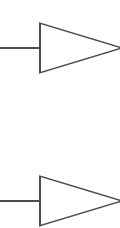

Bioreactors using isolated enzymes
Epoxy / hydroxy

fatty acid

derivatives

Figure 3: Biological/biotechnological routes for production of epoxy- and hydroxy fatty acids

1. Transgenic oil crops. Many plants produce oxygenated lipids as a component of their seed oils. An obvious way to prepare selectively oxygenated fatty acids is thus the isolation of plant oil which contains the desired compounds, the optimization of yields, or the genetic engineering of standard oil plants to accumulate oxyfunctionalized seed oils. Whereas the identification of oxygenated fatty acids in plant oils dates back by several decades, genetic engineering of oil crops producing oxygenated fatty acids is a very young discipline; most reports originate from the year 2000 or later, investigating the use of the model plant Arabidopsis thaliana (whose genome has been completely sequenced [6]) as a host system for seed-specific expression of hydroxylases or epoxidases $[3,7,8]$. More recently, the soybean (Brassica napis) was successfully engineered for the production of fatty acid epoxides [9]. Common to these reported processes is the relatively low content $(<60$ $\%$ ) of the desired oxyfunctionalized oils. Moreover, the fatty acid spectrum found in the seed oil was observed to contain oxygenated fatty acids different from those which were expected. Intensive research is still needed to obtain "chemical factories on a field", for valuable specialty products as much as for oxyfunctionalized commodities required at a large scale. 
2. Fermentation processes. The use of whole microbial cells for biotransformation requires the transport of reactants and products across the cell walls. Yields may be reduced by side reactions within the cell and by the expensive recovery process from dilute fermentation broths. Obvious advantages are that natural cofactors required for oxidation are available inside the cells, and that the oxidative enzymes are continuously expressed, even if they are bound to the cell's membranes. Thus, oxidation processes may ensue as long as the cell is alive.

Candida yeasts have been widely used for alkane or fatty acid oxygenation e. g. for the production of $\alpha, \omega$-dicarboxylic acids. First reports on the use of Candida strains in biotransformations focused on alkane functionalization, but it was shown that the same strains efficiently produced $\alpha, \omega$-dicarboxylic acids from saturated or unsaturated fatty acids. Mutant strains engineered for higher productivity were reported to produce up to $\sim 300 \mathrm{~g}$ of dioic acids per liter of fermentation broth $[10,11]$. Apart from yeasts, several bacteria such as Pseudomonades, Bacilli or Rhodococci are able to hydroxylate fatty acids in a terminal or subterminal manner $[4,12,13]$. While these processes have been studied to some extent, they do not yet allow to prepare oxyfunctionalized fatty acids at a sufficiently low price for commercial exploitation. For the synthesis of hydroxy fatty acids, E. coli was transformed with a suitable hydroxylase (P450 BM-3) and a fatty acid uptake system [14,15].

3. Bioreactors using isolated enzymes. Biocatalytic epoxidation- and hydroxylation of fatty acids using isolated enzymes in a bioreactor up to now is limited to either lipoxygenases (LOX, see chapter 1.6) or lipase-catalyzed perhydrolysis (see chapter 2.3) with subsequent self-epoxidation.

As cytochrome P450 monooxygenases and diiron cluster-containing monooxygenases are able to hydroxylate non-activated carbon-hydrogen bonds, they offer a particularily interesting possibility for selective fatty acid or fatty alcohol oxidation. However, up to now this is an issue of academic research only, as both enzyme classes require stochiometric amounts of the costly nicotinamide cofactors $\mathrm{NAD}(\mathrm{P}) \mathrm{H}$ for reductive activation of dioxygen. Various strategies for replacement of the natural cofactors by cheaper sources of reduction equivalents have been proposed (see chapter 2.2).

As a conclusion it must be stated that biocatalytic hydroxylation and epoxidation of fatty acids is still in its infancy. Large-scale applications seem to be possible in the near future only in very few cases (such as dicarboxylic acids by fermentation or fatty 
acid epoxides by lipase-catalyzed perhydrolysis), whereas most methods are to date predominantly an issue of academic interest. In the following sections a more detailed analysis is provided. Due to space limitation, special emphasis is given on P450 monooxygenases, due to the authors' interest. For this review, the patent literature has been covered only as to those references available from Chemical Abstract Services online.

\subsection{Natural functions of oxygenated fatty acids}

This section briefly discusses the occurrence and the possible functions of oxygenated fatty acids, recently termed oxylipins [16], in diverse forms of life. Readers who would like to learn more about the physiological role and metabolism of oxygenated fatty acids are referred to the literature cited. The natural sources and functions of oxygenated fatty acids are interesting as they show, (i) which organisms may be particularily useful for the prospecting of oxygenating enzymes and (ii) which natural function oxygenated fatty acids have, suggesting possible applications in a technical context.

While at least one hydroxy fatty acid (ricinoleic acid) is available from castor oil, there is no natural source of fatty epoxides worth exploitation. Nevertheless some plants, notably Vernonia galamensis and Euphorbia lagascae, produce up to $60 \%$ vernolic acid (12S, 13R-epoxy-9-cis-octadecenoic acid) in their seed oils. As these plants are poor oil producers, applications of this functionalized fatty acid have not been studied to a significant extent, and the manufacture of this oil is not yet commercialized.

On the other hand, the occurrence of a wide variety of oxygenated fatty acids has been reported in mammals, plants, fungi and bacteria.

In mammals, arachidonate (C20:4) $\omega$-hydroxylation is the first step in the arachidonic acid cascade. Oxygenated metabolites of arachidonic acid play a major role in blood pressure regulation and in the inflammatory process. They are signalling molecules in stress response to infection, allergy, exposure to food, drug and environmental harmful substances [17]. Prominent signalling molecules such as leucotrienes or prostaglandines are derived from oxidized arachidonic acid [18]. $\alpha$-Hydroxy fatty acids are also found in the sphingolipids of a wide variety of organisms, where they decrease membrane fluidity, in particular as a reaction to increasing temperature 
[19]. In nervous tissues of vertebrates, $\alpha$-hydroxy fatty acids play an indispensable role as part of hydroxycerebrosides [20].

In plants, arachidonic acid is quite rare, but phytooxylipins derived from linole(n)ic acid via the so-called lipoxygenase or oxylipin pathway are usually found. Thus, a whole series of compounds are derived from highly reactive 9- or 13hydroperoxyoctadecadi(tri)enoic acid [16]. Among these are natural pesticides, termed phytoalexins, which exhibit antibacterial and antifungal effects, as well as volatile aldehydes influencing the flavour or fragrance of many vegetables (reported for olive oil, tomatoes, cucumbers, etc. [21]). Most of these products seem linked to a plant's response towards attack: Apart from the phytoalexins, also the cutin monomers (the structural unit of the cuticle protecting the surface of all aerial parts of plants), and the wound hormone traumatin originate from the lipoxygenase pathway $[16,22]$.

Gram-negative bacteria contain $\beta$-hydroxy fatty acids as acyl moieties of cell wall lipids such as lipid A and ornithine lipid [23], whereas Gram-positive bacteria such as Bacillus strains may produce acylpeptides containing $\beta$-hydroxy fatty acid as antibiotic compounds (e. g. surfactin) [24,26]. Hydroxy fatty acids occur as corynomycolic acids in cell walls of pathogenic Mycobacteria (responsible for tuberculosis and leprosy) [25], and in sugar esters produced as biosurfactants by a number of alkane-degrading bacteria $[26,27]$.

\subsection{Some enzymes involved in oxyfunctionalization}

The $\mathrm{CH}$-bond of a fatty acid methylene group is one of the most stable chemical bonds whose breakage requires approximately $98 \mathrm{kcal} \mathrm{mol}^{-1}$. This energy is beyond the range of simple enzyme reactions and either requires a series of enzymatic reactions (as in the well known fatty acid-degrading $\beta$-oxidation pathway [18]) or a metal cofactor which harnesses the oxidative power of dioxygen to break this bond [28]. In view of fatty acid oxygenation, there are three main reaction types involved, namely (i) oxidation by P450 monooxygenases, (ii) oxidation by diiron center oxygenases and (iii) oxidation by lipoxygenases.

(i) P450 monooxygenases (EC 1.14.X.y) are an enzyme superfamily reported in all kingdoms of life. Cytochromes P450 contain a heme-thiolate prosthetic group and 
incorporate one atom of oxygen from dioxygen into their substrate while reducing the other oxygen atom to water. The reducing equivalents are delivered by the cofactor $\mathrm{NAD}(\mathrm{P}) \mathrm{H}$. P450 enzymes are related to catabolic as well as anabolic metabolism, catalyzing oxidative transformations of exogenous and endogenous compounds. With respect to fatty acids, P450s can act both as hydroxylases or as epoxidases of unsaturated fatty acids [29].

(ii) Diiron-center oxygenases (mainly in plants and bacteria) use a diiron-center for reductive oxygen activation, abstract a hydrogen atom from a $\mathrm{CH}$-bond and insert oxygen following a radical rebound mechanism, yielding epoxy- as well as hydroxy compounds [28]. They share high sequence homology with desaturases.

(iii) Lipoxygenases (linoleate : oxygen oxidoreductases; EC 1.13.11.12; LOXs) are limited to eukaryotes for fatty acid oxyfunctionalization [30]. They contain one nonheme iron per mole of protein and catalyze the regio- and stereoselective dioxygenation of polyenoic fatty acids forming S-configurated hydroperoxy derivatives. These highly reactive and cytotoxic hydroperoxides are immediately used for the biosynthesis of a vast range of compounds including epoxides, mono-, di- and trihydroxyderivatives, allene oxides, epoxyalcohols, aldehydes, oxoacids etc.

In the following, all three groups of enzymes will be further discussed. However, as many reviews can be found on LOX [31,32], the focus will be on the P450 monooxygenases and the diiron cluster enzymes.

\subsection{P450 monooxygenases}

\subsubsection{Introduction}

Cytochrome P450 enzymes belong to the class of monooxygenases (EC 1.14.x.y). They are widely distributed in nature [33] and play a key role in primary and secondary metabolism as well as in the detoxification of xenobiotic compounds. Common to all enzymes of the P450 superfamily is a heme group in the catalytic center which contains - in contrast to other hemoproteins - a fifth cysteine ligand coordinated to the iron atom. This feature is responsible for the characteristic spectral properties which gave P450 systems their name [34]: an absorption maximum at 450 $\mathrm{nm}$ in the presence of carbon monoxide 
From a functional point of view, all P450 enzymes catalyze the transfer of molecular oxygen to nonactivated aliphatic, to allylic or aromatic $X H$-bonds $(X:-C,-N,-S)$. Moreover, a remarkable number of P450 enzymes are capable of epoxidizing $\mathrm{C}=\mathrm{C}$ double bonds [33]. In certain cases the oxygenated compounds are not stable (e. g. acetals) and undergo subsequent reactions such as $\mathrm{N}$-demethylation.

P450 enzymes play a pivotal role in several metabolic pathways such as the metabolism of arachidonic acid to prostaglandines, leucotrienes and thromboxanes [35], the formation of cortisone by $11 ß$-hydroxylation of progesterone [36,37], the biosynthesis of insect and plant hormones [38,39], the formation of colors and odours of plants [40] and ergosterol biosynthesis in yeast [41] In the mammalian liver, P450s act as phase I enzymes [42], activating water-insoluble or barely water-soluble compounds for conjugation and elimination. Subsequent reactions are performed by phase II enzymes such as glutathione transferases, $\mathrm{N}$-acetyltransferases or sulfotransferases, which add further polar groups, rendering these metabolites watersoluble [42].

P450s recently came into the focus of biotechnologists, as they are able to carry out regio- and stereospecific oxidations at non-activated $\mathrm{C}-\mathrm{H}$ - and $\mathrm{C}=\mathrm{C}$-double bonds reactions which are possible only with molecules bearing certain functional groups (e. g. allylic alcohols) in synthetic organic chemistry. They might also be used in bioremediation. Thus, genetically engineered microorganisms containing suitable P450 monooxygenases have been proposed to, e. g., detoxify soil contaminated by polycyclic aromatic hydrocarbons $[43,44]$.

\subsubsection{Nomenclature and classification of cytochromes P450}

The P450 superfamily is one of the largest and oldest gene families [45]. By the end of 2002, more than 2500 putative $\mathrm{P} 450$ sequences had been reported (http://drnelson.utmem.edu/CytochromeP450.html). The number of P450 genes grows rapidly: In 2000, about 1000 sequences had been published [46], but recently the rice genome project alone has led to the identification of 481 new putative P450 genes. Despite a low sequence homology, all P450s adopt a characteristic threedimensional structure, as revealed by the 12 crystal structures known to date [47-58]. The nomenclature of P450 genes is based on primary sequence homologies. All P450 genes with a protein sequence homology $>40 \%$ belong to the same gene 
family, those with a sequence homology $>55 \%$ constitute a subfamily. To describe a P450 gene, it is recommended to use the italicized abbreviation 'CYP' for all P450 genes except for mouse and Drosophila, which are represented by italicized 'Cyp' letters. The CYP abbreviation is followed by an arabic number denoting the family, a letter designating the subfamily and a second arabic number representing the individual gene within the subfamily. For example, CYP102A2 represents the second gene identified within the P450 subfamily A of the P450 family 102.

Cytochromes P450 show a complex protein architecture, usually involving several cofactors and auxiliary proteins. Depending on the architecture of the overall protein complex, in particular the electron transfer (reductase) system which transfers reduction equivalents from the cofactors $\mathrm{NAD}(\mathrm{P}) \mathrm{H}$ they have been divided into four classes [59,60]:

- Class I: electrons are supplied from a flavoprotein reductase via an iron-sulfur protein to the P450. This type occurs mainly in mitochondrial systems and in most bacteria.

- Class II: electrons are supplied by a single FAD/FMN-reductase. This type of P450s is often located in the endoplasmatic reticulum

- Class III: they do not require reduction equivalents, as they use peroxygenated substrates which have already incorporated "activated" oxygen

- Class IV receives its electrons directly from NADH. This class is represented by a single member, nitric oxide synthase.

\subsubsection{P450 reaction cycle and its implications for synthetic applications}

The postulated reaction cycle of P450 monooxygenases $[33,61]$ is shown in Figure 4. Current knowledge about this cycle is mainly based on investigations using P450cam from Pseudomonas putida, which catalyzes the regio- and stereospecific hydroxylation of camphor to 5-exo-hydroxycamphor. 


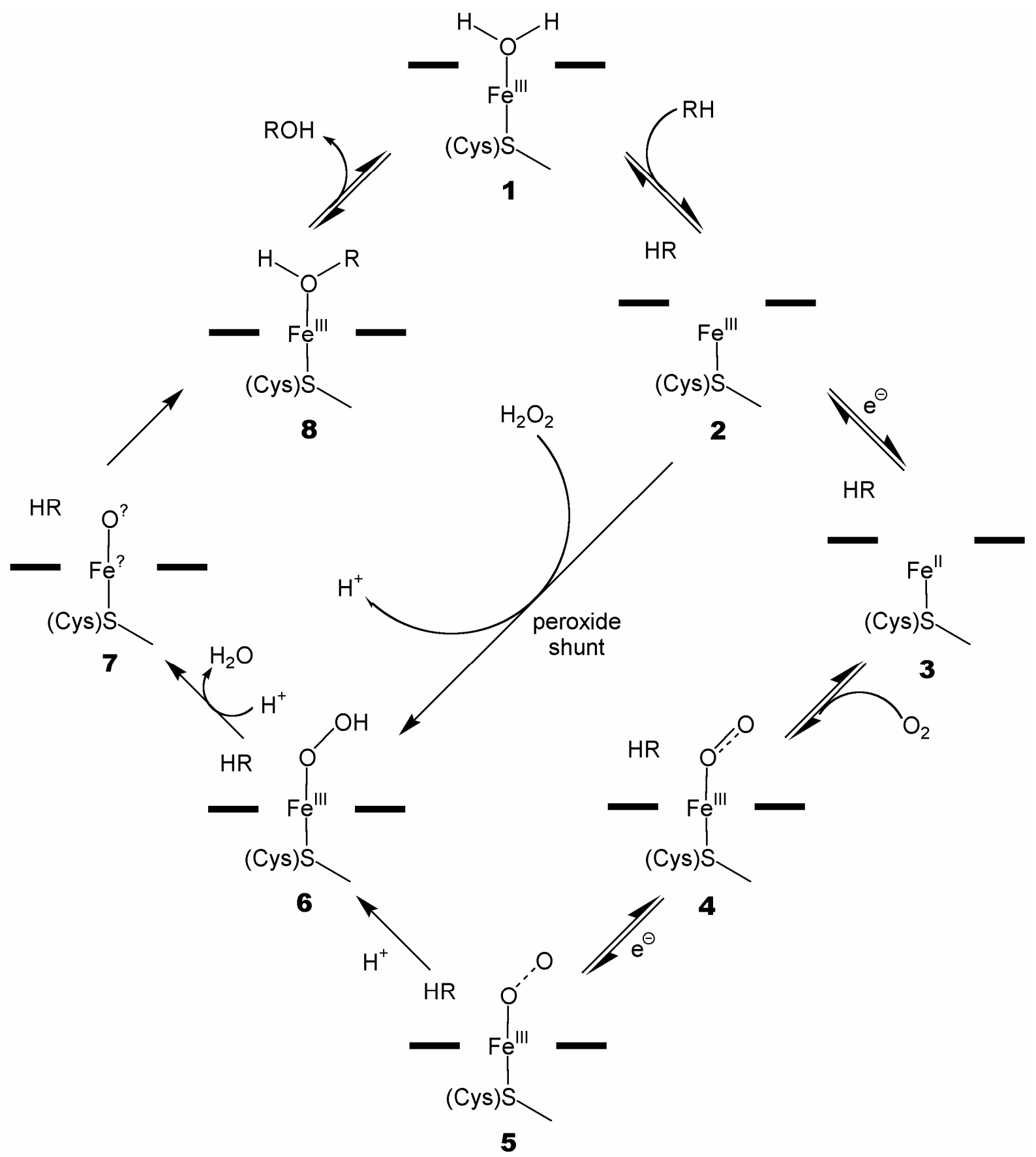

Figure 4: Postulated reaction cycle of P450 monooxygenases

In the inactive and substrate-free forms of P450s, the low-spin Fe $\mathrm{III}^{\mathrm{II}}$-center $\left(\mathrm{d}^{5}, \mathrm{~S}=\right.$ 0.5 ) is six-fold coordinated via a protoporphyrin IX system, a fifth cysteinate ligand and a water molecule (1 in Figure 4). On binding of a substrate molecule near to the heme the water ligand is displaced (2). The substrate binding induces a spin-state shift: The initial low-spin Fe $\mathrm{e}^{\text {III }}$ is converted to a high-spin Fe $\mathrm{e}^{\text {III }}$-complex, with the iron center far away from the porphyrin system plane, called out of plane structure. The redox potential is thereby increased from $\sim-300 \mathrm{mV}$ to $\sim-170 \mathrm{mV}$, facilitating the one-electron reduction of the iron center. An artificial 'shortcut' called shunt-pathway, 
mediated by strong oxidants such as peroxides, periodate or peracids, is leading to direct oxygenation of compound $\mathbf{2}$ to form the hydroperoxy-iron species $\mathbf{6}$. Under physiological conditions, one-electron reduction results in the formation of the highspin Fe" center $(S=2) 3$. This configuration with four unpaired electrons is well suited to bind triplet oxygen. The low-spin dioxy-iron(III) complex 4 was isolated and characterized by cryocrystallography revealing the iron atom in-plane to the porphyrin system. The next step, generating the peroxo-iron complex $\mathbf{5}$, requires another oneelectron reduction. The protons required for cleavage of the iron-bound dioxygen are delivered by a protein-water hydrogen-bonding network. The oxy-ferryl species 7, produced with simultaneous formation of water, has a short iron-to-oxygen distance, suggesting an $\mathrm{Fe}=\mathrm{O}$ bond. As knowledge about this complex originates mainly from crystal structures, the oxidation state of the iron and the electronic state of the heme could not be determined. The last step of the reaction cycle is the oxygenation, usually hydroxylation of the substrate.
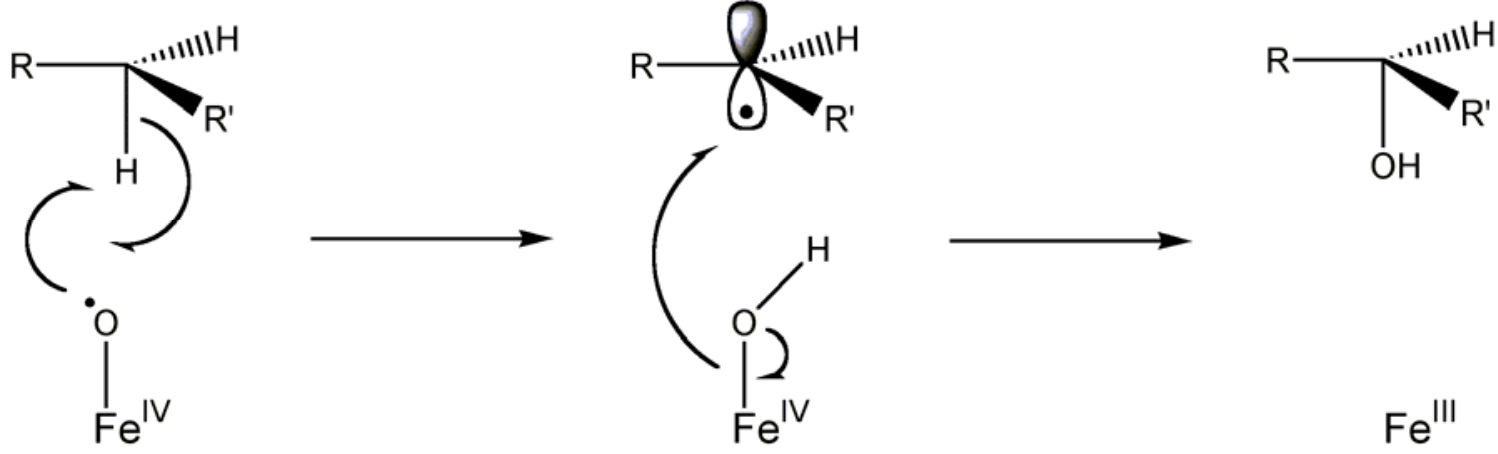

Figure 5: Rebound mechanism

The postulated rebound mechanism (Figure 5) is currently under debate due to mechanistic studies with ultrafast radical clocks to probe the presence of free radicals, suggesting a concerted oxene-insertion mechanism as indicated in Figure 3. This is especially true for epoxidation reactions, which are now suspected to be mediated by three different iron-oxygen species. The versatility in oxidative reactions may, in part, be attributed to the ability of P450 systems to use the peroxo-, hydroperoxo-, or oxenoid-iron species as the active oxidant depending on the substrate and the type of reaction effected [61, 62].

In a living organism, the two electrons required at distinct steps in this cycle are ultimately derived from the nicotinamide cofactors $N A D(P) H$. One major challenge for 
all attempts to construct a bioreactor with isolated P450s is to engineer an artificial electron supply system, as $\mathrm{NAD}(\mathrm{P}) \mathrm{H}$ is far too expensive for industrial applications.

\subsubsection{P450 monooxygenases in fatty acid / -alcohol modification}

Among the $~ 2500$ known P450s there are many fatty acid hydroxylases and epoxidases. Most enzymes showing hydroxylation activity with saturated fatty acids can also mediate epoxidation when unsaturated fatty acids are used as substrates. High regioselectivity generally implies high steric demands of the enzyme with respect to substrate fixation, orientation and control of the hydroxylation cycle. In the case of P450 monooxygenases, rational analysis is hampered by the lack of crystallographic data of enzyme-substrate complexes. From the few data available, e. g. a complex between CYP102A1 and palmitoleic acid [51] (which does not necessarily describe the productive state of enzyme - substrate interaction) - it can be implied that the acid group binds to positively charged or hydrogen-bonding residues near the entrance of the hydrophobic substrate acess channel, while the alkyl chain penetrates the channel and reaches the catalytic center in a geometric arrangement allowing (selective) hydroxylation [63]. Thus it is not surprising that many fatty acid-metabolizing P450 enzymes additonally accept fatty alcohols as substrates, though often with lower affinity due to weaker interactions of their functional group with the carboxylate binding site.

Fatty acid-hydroxylating P450 enzymes can be subdivided into terminal and subterminal fatty acid hydroxylases. With some enzymes the regiochemical outcome of the reaction depends on the chain-length of the fatty acid used. This may be due to a carboxylate binding site in a fixed distance from the catalytic iron, allowing terminal hydroxylation of the fatty acid spanning exactly this distance. The more a fatty acid exceeds this critical chain-length, the further in-chain the reaction will occur. Shorter fatty acids will not be hydroxylated at all, as their carbon chain will not reach the catalytic center. The hydroxylation mechanism (rebound) most likely involves a carbon-centered radical, which is lower in energy when located at a secondary $-\mathrm{CH}_{2}-$ group. Thus it is surprising, that $\omega$-hydroxylases generally show higher regiospecificity than their subterminally hydroxylating counterparts. On the other hand the possibility to perform the less favoured reaction specifically implies that for each 
position in the fatty acid carbon chain a specific P450 hydroxylase might be accessible either from natural sources or from genetic engineering techniques.

A large number of P450 enzymes, predominantly members of the gene families CYP2, CYP4, CYP52, CYP505 and CYP102, use fatty acids and their derivatives as substrates. Only well-characterized, readily available and biotechnologically interesting hydroxylases and epoxidases are presented in the following survey.

\subsubsection{The CYP102 family as a model for natural monooxygenase /} reductase fusions

CYP102A1, called P450 BM-3, is one of the most intensely studied P450 monooxygenases. This $118 \mathrm{kDa}$ enzyme, originally cloned from Bacillus megaterium represents a natural fusion protein, incorporating an FAD- and FMN-containing reductase (class II P450) and the P450-domain on a single peptide chain [64,65]. The P450 BM-3 heme domain was one of the first P450s whose structure was determined using x-ray crystallography [66]. By now, structures of various P450 BM-3 mutants as well as of the FMN-domain have been published [67]. CYP102A2 and CYP102A3 from Bacillus subtilis [68] show about $60 \%$ amino acid sequence identity when compared to P450 BM-3. These fatty acid monooxygenases are currently being investigated with respect to their biotechnological potential $[69,70]$. CYP116, a novel class of self-sufficient P450 from Rhodococci, displays properties closely paralleling those of the CYP102 family [71]. An eukaryotic counterpart of the CYP102 fusion proteins has lately been cloned, overexpressed and characterized: P450foxy (CYP505) from the fungus Fusarium oxysporum strongly resembles P450 BM-3 in terms of sequence homology and catalytic activities [72,73].

As the CYP102 monooxygenases are fusion proteins, the experimental setup for their application in organic syntheses is a lot easier compared to other P450s, which require one or two additional electron transport proteins for activity. Advantages of bacterial P450s are their solubility and higher stability [74]. In addition, all selfsufficient P450 monooxygenases (fusion proteins not requiring further proteinaceous electron transport components) characterized to date exhibit rather high turnover numbers $\left(>1000 \mathrm{~s}^{-1}\right)$ with their preferred substrates. 
P450 BM-3 has been subjected to numerous mutational studies [75-78], leading to enzyme variants hydroxylating shorter-chain fatty acids than the wildtype enzyme. Oliver et al showed that the amino acid at position 87 controls the regioselectivity of the fatty acid hydroxylation [79]. A single mutation (F87A) shifted the regioselectivity from subterminal to nearly exclusively terminal myristic and lauric acid hydroxylation. An amino acid exchange F87V converted P450 BM-3 into a stereo- and regioselective arachidonic acid $(14 S, 15 R)$-epoxygenase [80].

Generally, it was found that the regioselectivity of P450 BM-3 depends strongly on the chainlength of the fatty acid substrate.

Truan and co-workers determined the absolute configuration of the three hydroxylation products obtained from palmitic acid. They found a high enantiomeric excess for both $15 R$ - and $14 R$ - hydroxypalmitic acid (98\% ee) and a somewhat lower selectivity for $\omega-3$ hydroxylation yielding 13R-hydroxypalmitic acid (72\% ee) [81]. Arachidonic acid is oxidized by P450 BM-3 to nearly enantiomerically pure $(R)$-18hydroxyeicosatetraenoic acid (80 \% of total products) and 14S,15Repoxyeicosatrienoic acid [82]. The arachidonic acid analogues eicosapentaenoic and eicosatrienoic acid were quantitatively converted to $175,18 R$-epoxytetraenoic acid or a mixture of 17-, 18- and 19-hydroxyeicosatrienoic acid.

Recently P450 BM-3 has been the subject of several studies using laboratory evolution techniques aimed at improving stability against and activity with hydrogen peroxide, stability against organic solvents, $\mathrm{pH}$-stability as well as thermostability [78,83-85]. Screening for improved mutants was frequently based on the pNCA activity assay [86], which allows high-throughput colorimetric determination of subterminal fatty acid hydroxylation. In all cases considerable improvements of the desired properties could be achieved.

\subsubsection{The CYP52 family}

Members of the CYP52 family have been isolated from Candida species such as C. maltosa [87,88], C. apicola [89] and C. tropicalis [90]. They catalyze the conversion of $n$-alkanes to $\alpha, \omega$-dicarboxylic acids, where terminal hydroxylation of $n$-alkanes is rate-limiting, and $\omega$-hydroxylation of fatty acids ensues [91]. Candida species have long been known to produce $\alpha, \omega$-diacids. The potential of these conversions is 
stressed by the fact that most research in the field was done by industrial research laboratories, e. g. at Cognis (formerly Henkel) or Nippon Mining [92,5,10,93,94]. CYP52 is the only P450 family which always shows terminal hydroxylation, even if alkanes, alcohols or fatty acids of various chain lengths are used as substrates. The reactions leading to dicarboxylic acids are performed by a large class of P450 enzymes catalyzing all oxidation steps from terminal methyl groups to carboxylates. The further oxidation of terminal alcohols is catalyzed partially by P450s, but predominantly by fatty alcohol oxidases and dehydrogenases [95]. In the yeasts Candida maltosa and Candida tropicalis, eight [88] respectively ten [5] structurally related CYP52A genes and the corresponding reductase systems have been identified. The characterization of the Candida maltosa multigene CYP52 family led to a phylogenetic tree which describes the evolutionary distance among the members [96]. This is also reflected by the differences in their substrate specificity. For instance, CYP52A3 isoenzymes (P450 Alk1A, P450 Cm1) prefer alkanes, CYP52A4 (P450 Alk3A, P450 Cm2) and CYP52A5 (P450 Alk2A) hydroxylate alkanes and fatty acids to a similar extent, whereas CYP52A9 (P450 Alk5A), CYP52A10 and CYP52A11 prefer fatty acids as substrates. Scheller and coworkers found that a single P450 enzyme, CYP52A3 from C. maltosa, catalyzes the complete oxygenation cascade starting from $n$-alkanes to $\alpha, \omega$-dicarboxylic acids [91].

Compared to the fusion proteins regarded in the last chapter, the catalytic efficiency of the CYP52 family is at least a factor ten lower, reaching $80 \mathrm{~s}^{-1}$ with the best substrate [46]. Thus their application is more promising in genetically engineered yeasts, than in bioreactor applications, as a low activity in vivo can be compensated by a high level of gene expression and high cell densities.

\subsubsection{The CYP4 family}

In order to present this large P450 family adequately, general characteristics of the CYP4 family and of a mainly investigated member with respect to biotechnological applications, CYP4A1, are discussed in the following paragraphs.

CYP4 is one of the evolutionary oldest P450 families and contains 22 subfamilies [97]. CYP4 enzymes are primarily involved in hydroxylation of fatty acids, prostaglandines, leukotrienes and other eicosanoids in mammalian species [98]. The major fatty acid hydroxylating members are all part of the CYP4A subfamily. These 
enzymes all show strong preference for hydroxylation of the thermodynamically disfavoured $\omega$-position of arachidonic acid, suggesting a role in the mammalian arachidonic acid cascade. Another common feature of many CYP4 enzymes is their inducibility by hypolipidemic agents.

For P450s of the CYP4A subfamily, the preferred substrates are $\mathrm{C}_{12}$ to $\mathrm{C}_{20}$ fatty acids. Shorter $\left(\mathrm{C}_{7}-\mathrm{C}_{10}\right)$ ones are not hydroxylated, or only at low turnover. These $\mathrm{C}_{7^{-}}$ $\mathrm{C}_{10}$ fatty acids are converted by CYP4B1 isozymes with turnover numbers between 0.8 and 11 equiv min $^{-1}$ [99]. Reaction products of CYP4B1 are $\omega-1$ hydroxylated fatty acids or 2-hydroxy-alkanes.

The CYP4A1 enzyme, which was first isolated from rat liver [100], is one of the most investigated and active fatty acid hydroxylases of the CYP4A family. Inspired by the natural fusion protein P450 BM-3, Fisher and co-workers fused the rat liver NADPH reductase to the rat liver P450 4A1 [101]. Subsequent expression of the fused enzymes in $E$. coli resulted in fatty acid hydroxylation activity ranging from 10 to 30 equiv $\mathrm{min}^{-1}$. The activity of this fusion protein was enhanced 10-fold [102].

By the use of a reconstituted system with the human P450 reductase, Hoch and coworkers [103] reported high turnover numbers for rat P450 4A1 with values up to 649 equiv $\mathrm{min}^{-1}$ for the preferred substrate lauric acid, thus showing about ten-fold higher $\omega$-hydroxylation activity than the enzymes from the CYP52 family. Hoch and coworkers identified the amino acid residues which enable CYP4A enzymes to bind fatty acids tightly enough to hydroxylate them nearly exclusively at the less reactive $\omega$-position [104].

Remarkably, CYP4A1 hydroxylates not only lauric acid but also lauroyl alcohol, whereas dodecane is not a substrate [105].

\subsection{Diiron-cluster containing proteins}

\subsubsection{Introduction}

The topic of catalysis by proteins containing binuclear non-heme iron clusters is currently under intense study, as these enzymes catalyze a diverse set of reactions including hydroxylation, desaturation and epoxidation [106]. Diiron enzymes can be divided into two classes, namely soluble enzymes and a class of integral membrane enzymes, which show only very low sequence similarity to each other [28]. Because 
of the difficulties in obtaining large quantities of purified membrane proteins, progress in understanding the membrane bound class has lagged behind that of the soluble class. In the soluble enzymes, the two iron atoms are coordinated via four acidic and two histidine residues, whereas the membrane-bound enzymes use six histidines, as revealed by site-directed mutagenesis studies. The crystal structures of some soluble diiron enzymes have been resolved, providing precise active site geometries [107109]. This has led to models of the catalytic cycle of this enzyme class [110]. The reaction mediated by the integral membrane diiron enzymes are believed to proceed via a very similar mechanism.

Most, if not all, proteins containing a binuclear diiron cluster react with dioxygen as part of their functional processes [111]. Thus they are often referred to as "diiron-oxo" proteins.

The most intensively studied soluble hydroxylating diiron-oxo protein is methane monooxygenase (MMO), which produces methanol from methane and oxygen $[110,112]$. As this process is beyond standard chemistry, the mechanism of this enzyme has attracted great attention in the last years.

A rather well-characterized member of the integral membrane enzymes is the alkane $\omega$-hydroxylase from Pseudomonas oleovorans [113]. This enzyme is responsible for the oxygen- and rubredoxin-dependent oxidation of the methyl group of an alkane to produce the corresponding alcohol in a reaction that closely parallels that of MMO. In addition, this enzyme produces epoxides from alkenes, suggesting that epoxidation of double bonds can also be mediated by diiron enzymes [110].

With respect to fatty acid modification, diiron-oxo proteins were for a long time only recognized as desaturases [28]. This may be explained by the fact that all higher plants contain at least one membrane-bound oleate desaturase that catalyzes the oxygen-dependent insertion of a double bond between carbons 12 and 13 of lipidlinked oleic acid to produce linoleic acid. In contrast, only 14 species in 10 plant families have been found to accumulate the structurally related hydroxy fatty acid, ricinoleic acid, which is synthesized by an oleate hydroxylase that exhibits a high degree of sequence similarity to oleate desaturases [114]. This similarity is emphasized by the fact that as few as four amino acid substitutions can convert an oleate 12-desaturase to a hydroxylase [114]. Recently histidine-motif-containing genes encoding fatty acid epoxygenases have been isolated [115-117]. The 
corresponding enzymes regioselectively introduce epoxy groups into the 12-position of linoleic acid.

From a biotechnological point of view, the diiron-oxo monooxygenases share a considerable drawback with P450 enzymes: Both classes use electrons originating from the costly cofactor $\mathrm{NAD}(\mathrm{P}) \mathrm{H}$ for reductive oxygen activation. Moreover, just as P450s, diiron monooxygenases require electron transport chains delivering these reduction equivalents. In these electron transport systems pairs of electrons arising from NADH or NADPH are simultaneously transferred to a flavoprotein (ferredoxin$\mathrm{NADP}^{+}$oxidoreductase), that releases them one at a time to a carrier protein (ferredoxin) capable of carrying only a single electron. In photosynthetic tissues electrons arise from photosystem I and are directly transferred to ferredoxin, which in turn supplies the monooxygenase independently of ferredoxin-NADP ${ }^{+}$ oxidoreductase [28]. For overcoming the biotechnological disadvantage of a complicated electron supply system with an extremely expensive electron source, strategies paralleling those developed for P450 systems can be suggested.

\subsubsection{Mechanism of monooxygenation}

Details of the reaction mechanism of the soluble MMO are currently better understood than those of the membrane-bound fatty acid hydroxylases, epoxygenases and desaturases [110]. The proposal has been made, that all of these enzymes share a common activated diiron-oxygen intermediate [28]. Therefore, the same potential mechanisms can be envisaged for the integral membrane hydroxylases as for their soluble counterparts. As the exact reaction mechanism of diiron monooxygenases remains under debate, the following mechanistic consideration will only describe intermediates, which are commonly accepted.

In the resting form, the diiron center is in the oxidized (diferric or Fe $\mathrm{e}^{\text {III- }} \mathrm{Fe}^{\mathrm{III}}$ ) form ( $\mathbf{1}$ in Figure 6). Activation is initiated by 2-electron reduction via the corresponding reductase to produce the reduced (diferrous or $\mathrm{Fe}^{\text {Il}}-\mathrm{Fe}^{\| \prime}$ ) form 2. After reduction, molecular oxygen binds to the iron center resulting in the peroxo complex 3 . Scission of the $\mathrm{O}-\mathrm{O}$ bond gives rise to compound 4 , the key oxidizing intermediate responsible for subsequent hydrogen abstraction. At some point during oxygen activation a molecule of water is lost, but the precise timing of this step remains to be defined; consequently it is not shown in Figure 6. According to current models, this oxidizing 
species then abstracts a hydrogen atom forming a caged hydroxyl intermediate 6 and a carbon-centered radical. This in turn undergoes oxygen rebound in the fashion described for cytochrome P450 hydroxylases (see chapter 2.1.2) to yield the hydroxylated product.

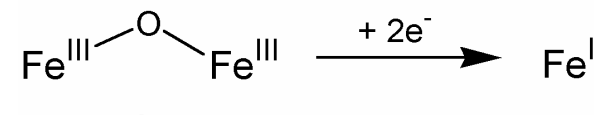

1

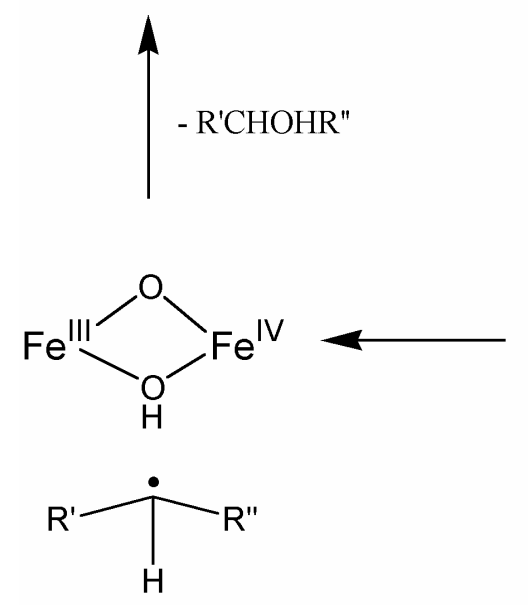

$\underline{6}$ $\underline{\mathbf{2}}$

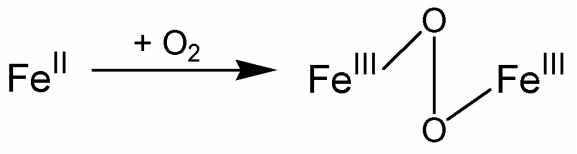

$\underline{3}$
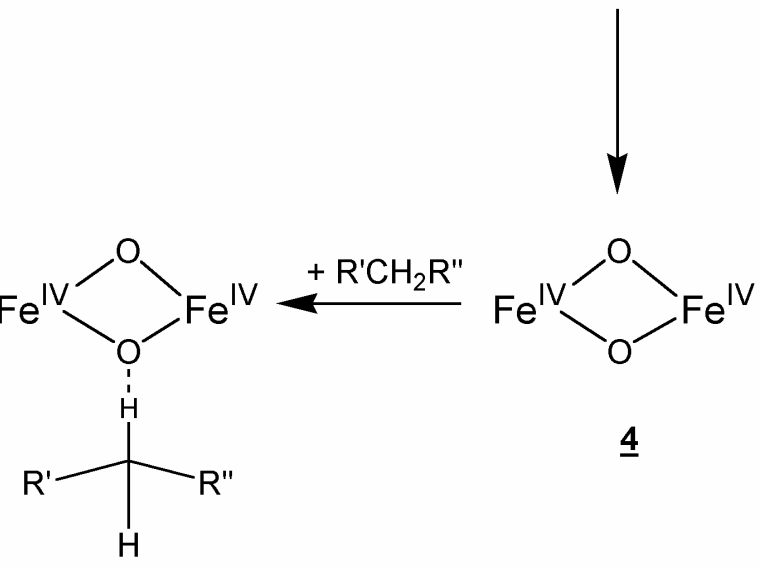

$\underline{5}$

Figure 6: Postulated reaction cycle of diiron monooxygenases

Interestingly compound 6 is also believed to be an intermediate of the desaturation mechanism [28]. Instead of rebound the abstraction of a second hydrogen would result in formation of a transient diradical that would spontaneously recombine to form the olefinic double bond. This close mechanistic similarity is reflected in the high sequence homology between hydroxylases and desaturases. Wheter the reaction outcome is hydroxylation or dehydration is a matter of subtle differences in substrate positioning relatively to the active center. Thus it can be rationalized why desaturases can be converted to hydroxylases and vice versa. Even bifunctional enzymes are known: The Lesquerella fendleri 12-hydroxylase also exhibits desaturase activity in vitro. 


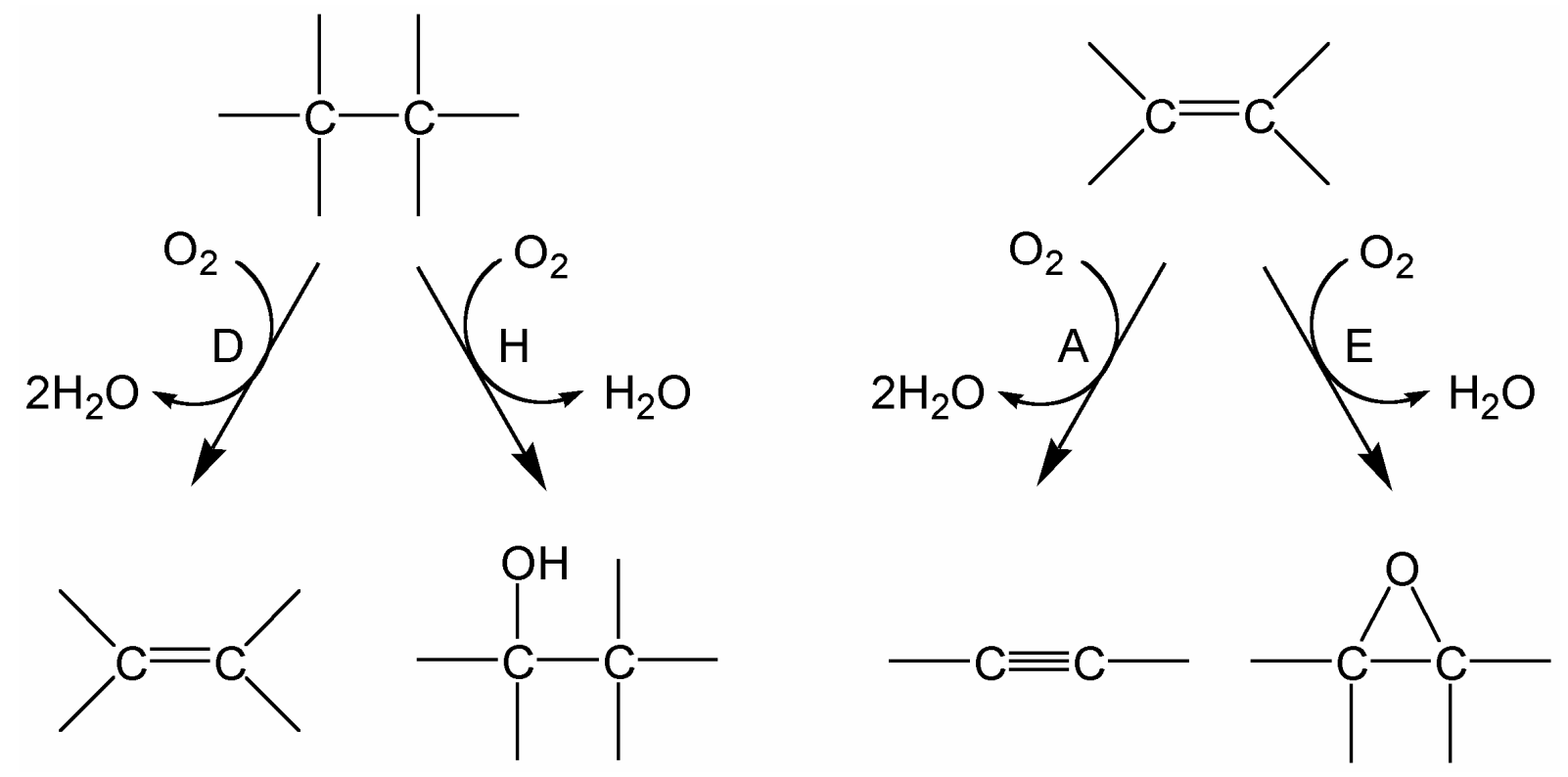

Figure 7: General scheme for fatty acid modification by diiron-oxo enzymes D: Desaturase; H: Hydroxylase; A: Acetylenase; E: Epoxidase

The same relationship was proposed for epoxidases and acetylenases, which are both acting on double bonds. This leads to the proposed general scheme for fatty acid modification by diiron-oxo enzymes (Figure 7) [28].

\subsubsection{Applications in fatty acid oxygenation}

Despite their occurrence in most plant species producing oils enriched in epoxy acids (only Euphorbiacea species use a P450 monooxygenase for fatty acid epoxidation), attempts to use diiron cluster-containing fatty acid monooxygenases in biotechnology are still limited [117]. As most available sequences originate from plants and are coding for integral membrane proteins, the primary focus was on attempts to engineer plants containing unusual fatty acids in their seed oils (see 2.1)

\subsection{Lipoxygenases}

Lipoxygenases (EC 1.13.11.12; LOXs) are non-heme iron dioxygenases which catalyze the stereospecific incorporation of dioxygen into the $1 Z, 4 Z$ pentadienyl 
system of polyunsaturated fatty acids to generate optically active (S)-dienic hydroperoxides (Figure 8) [31].
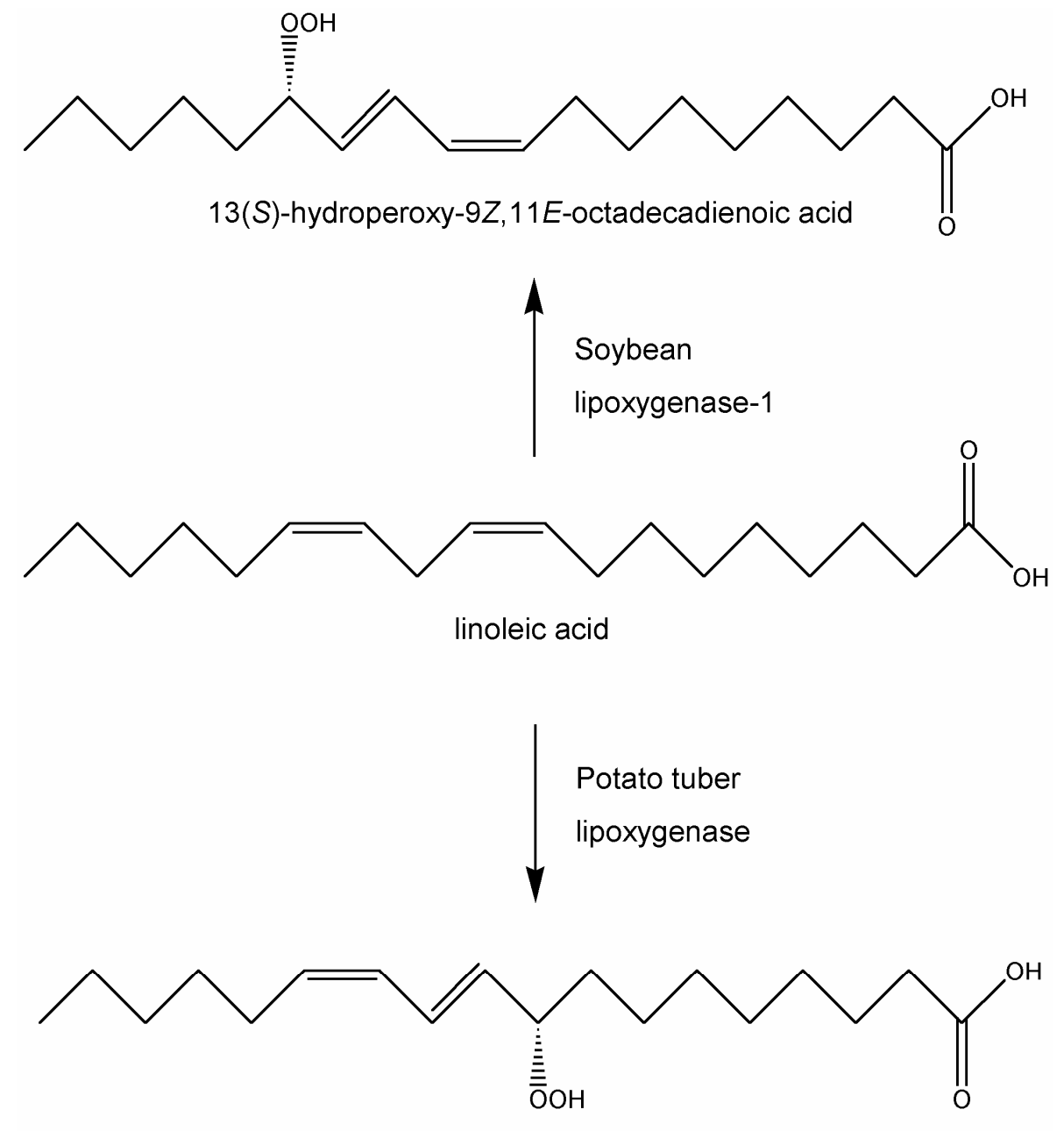

9(S)-hydroperoxy-9Z,11E-octadecadienoic acid

Figure 8: Lipoxygenase reactions and their regiospecificities

These compounds are potentially cytotoxic, as they can induce radical chain reactions. Thus, in living organisms they are immediately converted to a vast array of secondary metabolites (see chapter 1.1). Beside the dioxygenase reaction, LOX catalyze the secondary conversion of hydroperoxy lipids (hydroperoxidase reaction) and the formation of epoxy leukotrienes (leukotriene synthase reaction) [32].

As LOX are not directly hydroxylating or epoxidizing fatty acids, sequential reactions must be performed to yield hydroxy- or epoxy fatty acids. Thus they are not strictly subject to this review. Contrary to the monooxygenases discussed above, however, they are quite stable, active, and they posses a high degree of regio- and stereospecificity leading to compounds which are difficult to obtain by chemical 
synthesis. Because of this potential in the production of oxylipins a brief overview on biotechnological applications of LOXs will be given in the following paragraphs. Interested readers may find more information in reviews by lacazio and Feussner $[31,32]$.

LOXs are classified according to their regiospecificity using either linoleic acid with vegetal LOXs or arachidonic acid with other LOXs. For example soybean LOX isoenzyme-1 is classified as a 13-LOX, whereas potato tuber LOX is classified as a 9-LOX when - according to the conventions - linoleic acid is used as substrate (Figure 8). It should be noted that despite an opposite regiochemistry, the two enzymes both yield a hydroperoxide of $S$ absolute configuration, bearing a $2 E, 4 Z$ conjugated dienic system.

The LOX reaction may lead to various regioisomers. For example, a fatty acid such as arachidonic acid which contains three allylic methylene groups can be oxygenated by a LOX to 6 regio-isomeric hydroperoxy derivatives, namely the 15- and 11hydroperoxy derivative (originating from $\mathrm{C}_{13}$ hydrogen removal), the 12- and 8hydroperoxy derivative ( $\mathrm{C}_{10}$ hydrogen removal) and the 9- and 5-dioxygenated derivatives $\left(\mathrm{C}_{7}\right.$ hydrogen removal). LOXs displaying all these positional specificities are accessible, either from natural sources or by enzyme variants obtained by sitedirected mutagenesis [118].

\subsubsection{Applications of LOXs in organic synthesis}

It should be noted that the lipid hydroperoxides formed by LOXs can either be reduced to hydroxy compounds or processed further by enzymes of the lipoxygenase pathway. The need for reduction is not necessarily a disadvantage compared to other oxygenating enzymes like heme- and diiron monooxygenases. While these monooxygenases require reduction equivalents from extremely expensive cofactors or artificial reduction systems, the reductive step in transformations using LOX can be performed by relatively inexpensive chemical reducing agents such as $\mathrm{NaBH}_{4}, \mathrm{SnCl}_{2}$ or - after extraction of the reaction mixture - with triphenylphosphine (TPP).

\section{Application of enzymes in the oxygenation of fatty acid derivatives}


We will now discuss the use of enzymes in lipid oxyfunctionalization during the preparation of transgenic oil crops, during microbial fermentations and in bioreactors in more detail.

\subsection{Transgenic oil crops}

In an attempt to design new oilcrops yielding epoxy fatty acids, CYP726A1 from the Euphorbiacea Euphorbia lagasca was expressed in the seeds of various plant hosts. Some Euphorbiaceae species have long been known to contain 12-epoxy-cis-9octadecenoic acid (vernolic acid) in their seed oils. Expressing CYP726A1 under seed-specific promotors in transgenic tobacco or somatic soybean embryos resulted in formation of up to $15 \%(w / w)$ fatty acid epoxides in the seed oils $[9,117]$. Despite the low yields obtained yet, using a highly productive oilcrop as the soybean is a highly promising step for future developments.

A 112-epoxygenase isolated from Crepis palaestina $[115,119]$ has also been expressed in the model plant Arabidopsis thaliana under a seed-specific promotor, resulting in production of up to $8 \%$ of epoxy fatty acids, mainly 12,13-epoxy-cis-9octadecenoic acid [8]. Developing seeds of Arabidopsis were also used as host system for the expression of castor bean (Ricinus communis.) oleate $\Delta 12$ hydroxylase and the corresponding enzyme from Lesquerella fendleri [120]. Arabidopsis lines lacking the FAD3 ER $\Delta$-15-desaturase accumulated up to $50 \%$ hydroxy fatty acids (34 \% 18:1-OH; $16 \% 20: 1 \mathrm{OH})$ in their seed oils, when the castor hydroxylase was expressed [7].

Interest in using plants expressing P450 genes for production of oxygenated fatty acids is generally growing and the next years will possibly see significant improvements in this field [121,122].

\subsection{Microbial fermentations}

By blocking the $\beta$-oxidation pathway in Candida tropicalis and enhancing CYP52 expression, this species efficiently produces both saturated or unsaturated terminal diacids $\left(\mathrm{C}_{12}\right.$ to $\left.\mathrm{C}_{22}\right)$ from alkanes or fatty acids $[5,10]$. This process is highly productive: $300 \mathrm{~g}$ of diacids per liter of fermentation broth can be obtained [93]. 
Candida tropicalis M25 has been shown to produce 3-hydroxy dienedioic acids from linoleic acid [123].

Pseudomonas aeruginosa strain PR3 was used for hydroxylation of oleic and ricinoleic acid, yielding 7S,10S-dihydroxy-8E-octadecenoic acid and 7S,10S,12Rtrihydroxy-8E-octadecenoic acid, respectively. 7S,10S-dihydroxy-8E-octadecenoic, which is of pharmacological interest (see chapter 1.1), was obtained by this method in concentrations of nearly $10 \mathrm{~g} / \mathrm{l}$ [4].

Bacillus sphaericus strains were shown to produce 10-ketostearic acid from oleic acid [13]. Under optimized conditions, conversion of oleic acid reaches up to $60 \%$. Alternatively, up to $10 \mathrm{~g} / \mathrm{l}$ of 10-ketostearic acid can be obtained by fermentation of oleic acid with Sphingobacterium thalpophilum [12].

P450 BM-3, heterologously expressed in E. coli in combination with a fatty acid uptake system from Pseudomonas oleovorans has been used in vivo to produce mixtures of chiral 12-, 13- and 14-hydroxypentadecanoic acid in preparative scale at high optical purities $[15,14]$.

\subsection{Bioreactors}

Oxidation reactions using isolated enzymes may be most readily performed using LOXs, as they do not require reductive cofactors. Some applications are listed in the following paragraphs.

In 1989, Corey and co-workers [124] exploited the capacity of soybean lipoxygenase1 to carry out double dioxygenation of arachidonic acid to realize a simple synthesis of lipoxin $\mathrm{A}_{4}$, an important physiologically active eicosanoid of the arachidonic acid cascade. After reduction with $\mathrm{NaBH}_{4}$, two of the three asymmetric carbon centers of lipoxin $A_{4}$ in correct configuration had been introduced.

An analogous two-step chemo-enzymatic procedure using TPP for reduction was applied to the synthesis of the natural products coriolic acid [125] and dimorphecolic acid and to other hydroxy-polyunsaturated fatty acids $[126,127]$.

Viewed from the perspective of potential industrial applications it is important to understand that in the absence of oxygen, LOXs can catalyze an anaerobic reaction between their products and their substrates (hydroperoxidase reaction). This reaction is thought to generate radicals that are deleterious to the enzyme. Thus it is vital to 
maintain a sufficient concentration of dissolved oxygen in the reaction medium either by oxygen bubbling or by pressurization. Optimal reaction conditions were investigated by Martini et al [125] using a SOTELEM (Rueil Malmaison, France) stainless steel chemical reactor (MU 4004) which proved to be particularly suited to carry out lipoxygenation reactions. Thus, linoleic acid could be converted almost quantitatively to 13S-hydroperoxy-9Z,11E-octadecadienoic acid (95.5\%, $98 \%$ ee) at $5^{\circ} \mathrm{C}$ and $250 \mathrm{kPa}$ oxygen pressure, pH11 (0.1 M borate buffer), $0.1 \mathrm{M}$ substrate and $4 \mathrm{mg} \mathrm{ml}^{-1}$ soybean lipoxygenase. Especially remarkable is that quite high substrate concentrations of $0.1 \mathrm{M}$ were used, which largely exceeded the solubility of unsaturated fatty acids in the aqueous buffer system. Still, the reaction was complete within $30 \mathrm{~min}$.

In $1999 \mathrm{Hsu}$ et al [128] developed a packed-bed bioreactor for continuous oxygenation of linoleic acid. LOX immobilised in sol-gel matrices was used for these experiments.

Very recently, an industrial research group at Cognis, a company which for decades has been highly interested in oleochemistry, devised a new and efficient method to produce fatty acid hydroperoxides based on LOX. This process is conducted in an oil (or fatty acid) / water two phase system containing LOX and catalase. Molecular oxygen as primary oxidant was substituted by hydrogen peroxide, resulting in higher turnover numbers [129].

Hydrogen peroxide is also used as oxidant in the chemoenzymatic synthesis of fatty epoxides by lipase-catalyzed perhydrolysis. A group at Novo Nordisk A/S first discovered that unbranched saturated fatty acids with four to 22 carbon atoms can be converted to peroxy fatty acids using hydrogen peroxide, and Novozyme 435, an immobilized lipase B from Candida antarctica [130]. If an unsaturated fatty acid or its ester is treated with $\mathrm{H}_{2} \mathrm{O}_{2}$ in the presence of Novozyme 435, "self"-epoxidation occurs [131]. First, the unsaturated fatty acid is converted to an unsaturated peroxy fatty acid (only this step is catalyzed by the lipase). Subsequently, the unsaturated peroxy acid epoxidizes "itself" in an uncatalyzed Prileshajev (Figures 1 and 2) epoxidation. Depending on the chainlength, peroxy fatty acid yields from 70 to $95 \%$ were obtained [131],[132]. In addition to the production of partially or completely epoxidized fatty acids, this method is capable to produce epoxidized plant oils [132] and fatty alcohol epoxides [133]. The epoxidation processes described by Warwel and Rüsch have already been carried out on the kilogram scale. If further successful, 
they may allow to substitute the problematic Prileshajev-epoxidation by lipasecatalyzed perhydrolysis.

Several years ago an enzymatic activity termed peroxygenase was found and characterized in plant extracts by Blee [16] and Hamberg [134] while investigating the fate of lipid hydroperoxides originating from the lipoxygenase reaction. Peroxygenase, a hemoprotein, catalyzes the inter- and intramolecular transfer of oxygen from a fatty acid hydroperoxide to form epoxides from unsaturated fatty acids. It was found, that an external oxidant such as hydrogen peroxide or cumene hydroperoxide could be used as an alternative source of oxygen. Hamberg demonstrated that oat (Avena sativa) seeds are a good source of peroxygenase. Starting from this point, Piazza et al devised a method for rapid isolation and immobilization of this enzyme on membranes and conducting epoxidation reactions in organic solvents. Using t-butyl hydroperoxide as oxidant, oleic acid, linoleic acid and arachidonic acid could be converted nearly quantitatively to their corresponding epoxides [135].

The enzymatic reactions described so far are performed easily and without involvement of cofactors. This situation changes, if reactions mediated by cytochromes P450 are considered. Thus, the following considerations to date are predominantly an issue of academic interest.

One possibility for applications of isolated P450 enzymes is to use the "shunt pathway". Addition of cheap and readily available hydrogen peroxide (or of an organic peroxide) to the initial enzyme-substrate complex can supply both the electrons and the oxygen atom required to form the reactive iron-oxygen intermediate, the species which inserts the oxygen atom into the substrate (Figure 4). Unfortunately, the stoichiometric use of peroxides is quite inefficient, and may quickly lead to inactivation of the enzyme [85].

In this context the recent identification of two unusual peroxygenase P450s is interesting. They lack a threonine residue which is highly conserved among P450 monooxygenases and thought to be essential for dioxygen activation. Thus these enzymes are not cofactor-dependent and therefore well suited for in vitro applications. Fatty acid hydroxylase from Sphingomonas paucimobilis (CYP152B1) efficiently produces (S)- $\alpha$-hydroxy fatty acids [136,137], whereas its close relative CYP152A1 (alternatively called ybdT gene) from Bacillus subtilis attacks the $\alpha$ carbon as well as the $\beta$-carbon of myristic acid [138]. As both enzymes posess very 
high affinity to hydrogen peroxide, these conversions require only very low $\mathrm{H}_{2} \mathrm{O}_{2}$ concentrations, thus tempering the deleterious effects of $\mathrm{H}_{2} \mathrm{O}_{2}$ on the enzyme. Enhanced stability against and activity with $\mathrm{H}_{2} \mathrm{O}_{2}$ has also been achieved by laboratory evolution of P450 BM-3 [139].

Direct electron supply from electrodes $[140,141]$ is another option for delivering reduction equivalents to the catalytic iron of P450s. It was found to result in very low productivity, but could be enhanced by the use of soluble electron mediators such as cobalt(III)sepulchrate [142] in combination with a CYP4A1/reductase fusion protein [102]. Recently the electrochemical reduction of the prosthetic flavin of a reductase mediated by an organometallic rhodium-complex was investigated and applied to the synthesis of styrene oxide [143]. This method has the potential to be applied to all flavin-containing reductases and thus can possibly be used for the synthesis of oxygenated fatty acid derivatives.

Schwaneberg and coworkers used the electron mediator cobalt(III)-sepulchrate [142] and zinc dust as electron source to drive the catalytic cycle of P450 BM-3, resulting in turnover numbers reaching $50 \%$ of those with the natural cofactor [144,145].

Finally, another method to circumvent the stochiometric need of reduced cofactors is their regeneration (Figure 9), which must be highly efficient to reduce the cofactor costs to an economically acceptable level.

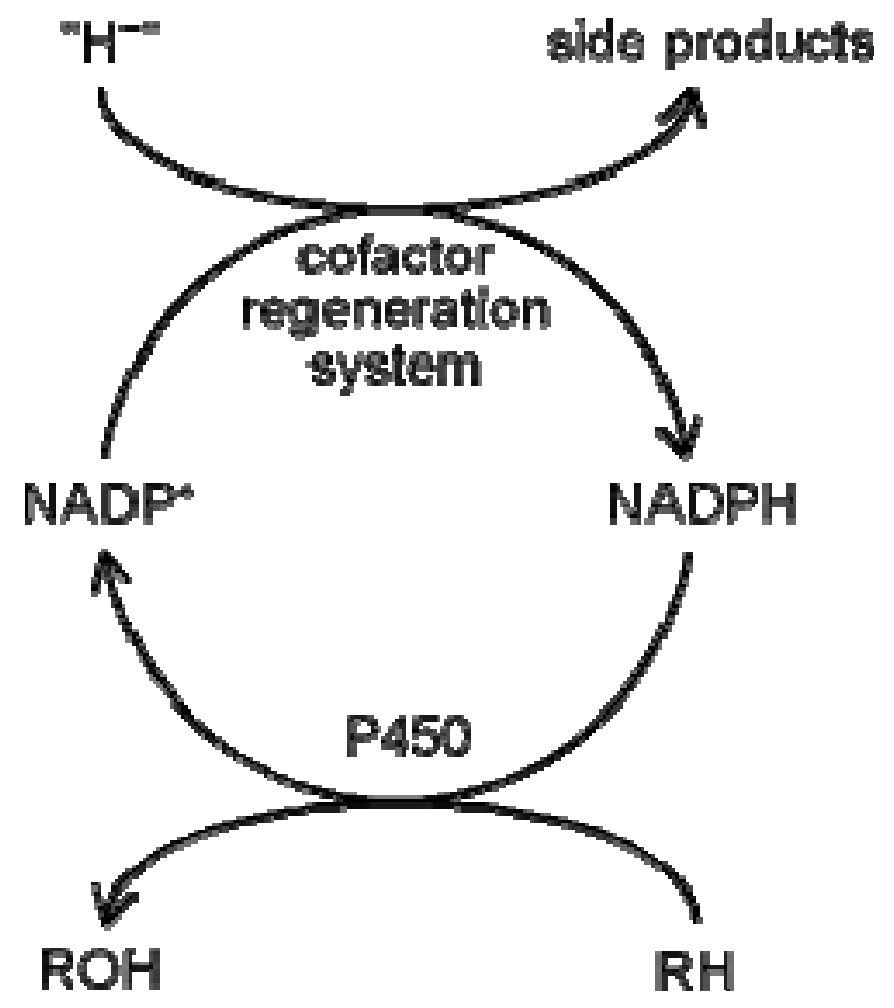

Figure 9: Cofactor recycling systems for cytochromes P450; 
"H-" may be derived from enzymatic oxidation (dehydrogenases), from oxidation by organometallic complexes or from electrochemical sources

In this context enzymatic [146] and organometallic [147] approaches have been suggested for hydride transfer to $\operatorname{NAD}(P)^{+}$. The required electrons may be derived from formate or glucose oxidation using the respective dehydrogenases(formate- or glucose dehydrogenase), or from electrochemical sources in case of organometallic rhodium-complexes.

Sol-gel encapsulation of P450 BM-3 mutants in combination with genetically engineered $\mathrm{NADP}^{+}$-dependent formate dehydrogenase (FDH) [148] resulted in a heterogeneous, stable and self-sufficient hydroxylation biocatalyst capable to recycle NADPH from NADP ${ }^{+}$(Figure 9) [149]. Side products of this hydroxylation cycle are only carbon dioxide and water.

\section{Outlook}

The information provided in this article, and especially the examples given above, demonstrate that fatty acid-oxygenating enzymes are indeed a versatile and useful class of biocatalysts. On the other hand, industrial applications of this class of enzymes are yet scarce. This is not surprising if the drawbacks - need of expensive cofactors, low stability under reaction conditions or low turnover numbers -associated with the biocatalysts under investigation are considered. On the other hand in vivo processes are, with the remarkable exception of dioic acid production, not developed far enough to be established at industrial scale. However in academic as well as industrial research laboratories a lot of efforts are made to overcome the problems in biocatalytic oxidation. Especially the tremendous development of directed evolution techniques, eventually in combination with rational enzyme engineering based on the growing insights into protein structures and functions, could help to overcome the problems yet unresolved. Cytochromes P450 and diiron cluster-containing monooxygenases could be used in preparative synthesis as soon as an efficient method for substitution of their cofactors $\mathrm{NAD}(\mathrm{P}) \mathrm{H}$ will be found.

As organic chemistry to date does not present efficient tools for (stereo)selective oxygenation of fatty acid carbon chains, biocatalytic processes have a great potential to be the first technique providing access to compounds yet not obtainable at 
commercial scale. This would undoubtly open up the possibility to develop new products based on oleochemistry. It is the consideration of the authors that at least some of the enzymes presented here will find applications in future.

\section{Acknowledgement}

The authors are grateful to Dr. Vlada Urlacher for helpful discussions.

\section{References}

1. K Hill. Fats and oils as oleochemical raw materials. J Oleo Sci 50:433-444, 2001.

2. M Rüsch gen Klaas, $\mathrm{S}$ Warwel. Complete and partial epoxidation of plant oils by lipase-catalyzed perhydrolysis. Ind Crops and Products 9:125-132, 1999.

3. M Smith, H Moon, L Kunst. Production of hydroxy fatty acids in the seeds of arabidopsis thaliana. Biochem Soc Trans 28:947-950, 2000.

4. TM Kuo, AC Lanser. Factors influencing the production of a novel compound, 7,10dihydroxy-8(e)-octadecenoic acid, by pseudomonas aeruginosa pr3 (nrrl b-18602) in batch cultures. Curr Microbiol 47:186-191, 2003.

5. CR Wilson, DL Craft, LD Eirich, M Eshoo, KM Madduri, CA Cornett, AA Brenner, M Tang, JC Loper, M Gleeson. Cytochrome p 450 monooxygenase and nadph cytochrome p 450 oxidoreductase genes and proteins related to the w-hydroxylase complex of candida tropicalis, PCT Int. Appl. (Henkel Corporation, USA; et al.). WO. 200 pp., 2000.

6. Arabidopsis Genome Initiative. Analysis of the genome sequence of the flowering plant arabidopsis thaliana. Nature 408:796-815, 2000. 
7. MA Smith, H Moon, G Chowrira, L Kunst. Heterologous expression of a fatty acid hydroxylase gene in developing seeds of arabidopsis thaliana. Planta 217:507-516, 2003.

8. S Singh, S Thomaeus, M Lee, A Green, S Stymne. Inhibition of polyunsaturated fatty acid accumulation in plants expressing a fatty acid epoxygenase. Biochem Soc Trans 28:940-942, 2000.

9. B Cahoon Edgar, G Ripp Kevin, E Hall Sarah, B McGonigle. Transgenic production of epoxy fatty acids by expression of a cytochrome p450 enzyme from euphorbia lagascae seed. Plant Phys 128:615-624., 2002.

10. S Picataggio, T Rohrer, LD Eirich. Method for increasing the w-hydroxylase activity of candida tropicalis in the manufacture of a,w-dicarboxylic acids, PCT Int. Appl. (Henkel Research Corp., USA). WO. 52 pp., 1991.

11. KD Green, MK Turner, JM Woodley. Candida cloacae oxidation of long-chain fatty acids to dioic acids. Enzyme Microb Technol 27:205-211, 2000.

12. TM Kuo, AC Lanser, LK Nakamura, CT Hou. Production of 10-ketostearic acid and 10-hydroxystearic acid by strains of sphingobacterium thalpophilum isolated from composted manure. Curr Microbiol 40:105-109, 2000.

13. TM Kuo, LK Nakamura, AC Lanser. Conversion of fatty acids by bacillus sphaericuslike organisms. Curr Microbiol 45:265-271, 2002.

14. S Schneider, MG Wubbolts, G Oesterhelt, D Sanglard, B Witholt. Controlled regioselectivity of fatty acid oxidation by whole cells producing cytochrome p450bm3 monooxygenase under varied dissolved oxygen concentrations. Biotechnol Bioeng 64:333-341, 1999.

15. S Schneider, MG Wubbolts, D Sanglard, B Witholt. Biocatalyst engineering by assembly of fatty acid transport and oxidation activities for in vivo application of 
cytochrome p-450bm-3 monooxygenase. Applied and Environmental Microbiology 64:3784-3790, 1998.

16. E Blee. Biosynthesis of phytooxylipins. The peroxygenase pathway. Fett/Lipid 100:121-127, 1998.

17. KC Nicolaou, JY Ramphal, NA Petasis, MH Serhan. Lipoxins and related eicosanoids: Biosynthesis, biological properties and chemical synthesis. Angew Chem Int Ed Engl 30:1100-1116, 1991.

18. D Voet,JG Voet. Biochemie. Biochemie. Weinheim: VCH 2000, pp 620-631.

19. K Kaya, CS Ramesha, GA Thompson, Jr. On the formation of alpha-hydroxy fatty acids. Evidence for a direct hydroxylation of nonhydroxy fatty acid-containing sphingolipids. J Biol Chem 259:3548-3553, 1984.

20. PF Ki, Y Kishimoto, EE Lattman, EF Stanley, JW Griffin. Structure and function of urodele myelin lacking alpha-hydroxy fatty acid-containing galactosphingolipids: Slow nerve conduction and unusual myelin thickness. Brain Res 345:19-24, 1985.

21. JJ Salas, J Sanchez. Hydroperoxide lyase from olive (olea europaea) fruits. Plant Sci (Shannon, Ireland) 143:19-26, 1999.

22. E Blee,F Schuber. Biosynthesis of cutin monomers: Involvement of a lipoxygenase/peroxygenase pathway. Plant Journal 4:113-123, 1993.

23. Y Nakagawa, K Kishida, Y Kodani, T Matsuyama. Optical configuration analysis of hydroxy fatty acids in bacterial lipids by chiral column high-performance liquid chromatography. Microb Immunol 41:27-32, 1997.

24. K Hosono ,H Suzuki. Acylpeptides, the inhibitors of cyclic adenosine 3'.5'monophosphate phosphodiesterase. J Antibiot 36:667-673, 1983.

25. E Janczura, C Abou-Zeid, C Gailly, C Cocito. Chemical identification of some cellwall components of microorganisms isolated from human leprosy lesions. Zentralbl Bakteriol Mikrobiol Hyg [A] 251:114-125, 1981. 
26. AK Koch, O Kappeli, A Fiechter, J Reiser. Hydrocarbon assimilation and biosurfactant production in pseudomonas aeruginosa mutants. J Bacteriol 173:42124219, 1991.

27. JC Philp, MS Kuyukina, IB Ivshina, SA Dunbar, N Christofi, S Lang, V Wray. Alkanotrophic rhodococcus ruber as a biosurfactant producer. Appl Microbiol Biotechnol 59:318-324, 2002.

28. J Shanklin, EB Cahoon. Desaturation and related modifications of fatty acids. Ann Rev Plant Phys and Plant Mol Biol 49:611-641, 1998.

29. D Werck-Reichhart, R Feyereisen. Cytochromes p450: A success story. Genome Biol. 1:3001-3012, 2000.

30. AR Brash. Lipoxygenases: Occurrence, functions, catalysis and acquisition of substrate. J Biol Chem 274:23679-23682, 1999.

31. I Feussner, H Kühn, Application of lipoxygenases and related enzymes for the preparation of oxygenated lipids. In Enzymes in Lipid Modification, UT Bornscheuer, Editor. 2000, Wiley-VCH: Weinheim, New York. pp 309-336.

32. G Iacazio, D Martini-Iacazio, Properties and applications of lipoxygenases, In Enzymes in Lipid Modification, UT Bornscheuer, Editor. 2000, Wiley VCH: Weinheim, New York. pp 337-359.

33. DF Lewis. Cytochromes p450: Structure, function and mechanism, vol 1. London: Taylor \& Francis 1996.

34. T Omura, RJ Sato. The carbon monoxide-binding pigment of liver microsomes. I evidence for its hemoprotein nature. J Biol Chem 239:2370-2378, 1964.

35. D Kupfer, KA Holm. Prostaglandin metabolism by hepatic cytochrome p450. Drug Metab Rev 20:753-764, 1989.

36. A el-Monem, H el-Refai, AR Sallam, H Geith. Microbial 11 -hydroxylation of progesterone. Acta Microbiol Pol B 4:31-36, 1972. 
37. L Sallam, N Naim, A Zeinel-Abdin Badr, A El-Refai. Bioconversion of progesterone with cell preparations with aspergillus niger 171. Rev Latinoam Microbiol 19:151153, 1977.

38. R Feyereisen. Insect p450 enzymes. Annu Rev Entomol 44:507-533, 1999.

39. F Durst, DP O'Keefe. Plant cytochromes p450: An overview. Drug Metab Drug Interact 12:171-187, 1995.

40. TA Holton, F Brugliera, DR Lester, Y Tanaka, CD Hyland, JG Menting, CY Lu, E Farcy, TW Stevenson, EC Cornish. Cloning and expression of cytochrome p450 genes controlling flower colour. Nature 366:276-279, 1993.

41. D Berg, M Plempel, K Buchel, G Holmwood, K Stroech. Sterol biosynthesis inhibitors. Secondary effects and enhanced in vivo efficay. Ann N Y Acad Sci 544:338-347, 1988.

42. JA Goldstein,MB Faletto. Advances in mechanisms of activation and deactivation of environmental chemicals. Environ Health Perspect 100:169-176, 1993.

43. S Harayama. Polycyclic aromatic hydrocarbon bioremediation design. Curr Opin Biotechnol 8:268-273, 1997.

44. DG Kellner, SA Maves, SG Sligar. Engineering cytochrome p450s for bioremediation. Curr Opin Biotechnol 8:274-278, 1997.

45. DR Nelson,HW Strobel. Evolution of cytochrome p450 proteins. Mol Biol Evol 5:199-220, 1988.

46. U Schwaneberg, UT Bornscheuer. Fatty acid hydroxylations using p450 monooxygenases. , In Enzymes in Lipid Modification, UT Bornscheuer, Editor. Wiley VCH: Weinheim, New York, 2000. pp:394-414.

47. TL Poulos, BC Finzel, AJ Howard. High-resolution crystal structure of cytochrome p450cam. J Mol Biol 195:687-700., 1987. 
48. CA Hasemann, KG Ravichandran, JA Peterson, J Deisenhofer. Crystal structure and refinement of cytochrome p450terp at 2.3 a resolution. J Mol Biol 236:1169-1185., 1994.

49. K Nakahara, H Shoun, S Adachi, T Iizuka, Y Shiro. Crystallization and preliminary xray diffraction studies of nitric oxide reductase cytochrome p450nor from fusarium oxysporum. J Mol Biol 239:158-159., 1994.

50. JR Cupp-Vickery, TL Poulos. Structure of cytochrome p450eryf involved in erythromycin biosynthesis. Nat Struct Biol 2:144-153, 1995.

51. H Li, TL Poulos. The structure of the cytochrome p450bm-3 haem domain complexed with the fatty acid substrate, palmitoleic acid. Nat Struct Biol 4:140-146, 1997.

52. SY Park, K Yamane, S Adachi, Y Shiro, KE Weiss, SG Sligar. Crystallization and preliminary x-ray diffraction analysis of a cytochrome p450 (сур119) from sulfolobus solfataricus. Acta Crystallogr D Biol Crystallogr 56:1173-1175., 2000.

53. PA Williams, J Cosme, A Ward, HC Angove, D Matak Vinkovic, H Jhoti. Crystal structure of human cytochrome p450 2c9 with bound warfarin. Nature 424:464-468, 2003.

54. LM Podust, TL Poulos, MR Waterman. Crystal structure of cytochrome p450 14alpha -sterol demethylase (cyp51) from mycobacterium tuberculosis in complex with azole inhibitors. Proc Natl Acad Sci U S A 98:3068-3073., 2001.

55. LM Podust, Y Kim, M Arase, BA Neely, BJ Beck, H Bach, DH Sherman, DC Lamb, SL Kelly, MR Waterman. The 1.92-a structure of streptomyces coelicolor a3(2) cyp154c1. A new monooxygenase that functionalizes macrolide ring systems. J Biol Chem 278:12214-12221, 2003.

56. JK Yano, F Blasco, H Li, RD Schmid, A Henne, TL Poulos. Preliminary characterization and crystal structure of a thermostable cytochrome p450 from thermus thermophilus. J Biol Chem 278:608-616, 2003. 
57. EE Scott, YA He, MR Wester, MA White, CC Chin, JR Halpert, EF Johnson, CD Stout. An open conformation of mammalian cytochrome p450 2b4 at 1.6-a resolution. Proc Natl Acad Sci U S A 100:13196-13201, 2003.

58. S Nagano, H Li, H Shimizu, C Nishida, H Ogura, PR Ortiz De Montellano, TL Poulos. Crystal structures of epothilone d-bound, epothilone b-bound, and substratefree forms of cytochrome p450epok. J Biol Chem. [Epub ahead of print], 2003.

59. KW Degtyarenko. Structural domains of p450-containing monooxygenase systems. Protein Eng. 8:737-747, 1995.

60. JA Peterson, SE Graham. A close family resemblance: The importance of structure in understanding cytochromes p450. Structure 6:1079-1085, 1998.

61. PR Ortiz de Montellano,JJ De Voss. Oxidizing spezies in the mechanism of cytochrome p450. Nat. Prod. Rep. 19:477-493, 2002.

62. ADN Vaz, DN McGinnity, MJ Coon. Epoxidation of olefins by cytochrome p450: Evidence from site-specific mutagenesis for hydroperoxo-iron as an electrophilic oxidant. Proc. Natl. Acad. Sci. USA 95:3555-3560, 1998.

63. PR Ortiz de Montellano, WK Chan, SF Tuck, RM Kaikus, NM Bass, JA Peterson. Mechanism-based probes of the topology and function of fatty acid hydroxylases. FASEB J. 6:695-699, 1992.

64. LO Narhi, AJ Fulco. Characterization of a catalytically self-sufficient 119,000-dalton cytochrome p-450 monooxygenase induced by barbiturates in bacillus megaterium. $\mathrm{J}$ Biol Chem 261:7160-7169, 1986.

65. LP Wen, AJ Fulco. Cloning of the gene encoding a catalytically self-sufficient cytochrome p-450 fatty acid monooxygenase induced by barbiturates in bacillus megaterium and its functional expression and regulation in heterologous (escherichia coli) and homologous (bacillus megaterium) hosts. J Biol Chem 262:6676-6682, 1987. 
66. KG Ravichandran, SS Boddupalli, CA Hasermann, JA Peterson, J Deisenhofer. Crystal structure of hemoprotein domain of p450bm-3, a prototype for microsomal p450's. Science 261:731-736, 1993.

67. IF Sevrioukova, H Li, H Zhang, JA Peterson, TL Poulos. Structure of a cytochrome p450-redox partner electron-transfer complex. Proc Natl Acad Sci U S A 96:18631868, 1999.

68. MC Gustafsson, CN Palmer, CR Wolf, C von Wachenfeldt. Fatty-acid-displaced transcriptional repressor, a conserved regulator of cytochrome p450 102 transcription in bacillus species. Arch Microbiol 176:459-464, 2001.

69. O Lentz, V Urlacher, RD Schmid. Comparison of cyp102a3 with cyp102a1. J Biotechnol in press, 2004.

70. M Budde. Publication in preparation, 2004.

71. R De Mot,AH Parret. A novel class of self-sufficient cytochrome p450 monooxygenases in prokaryotes. Trends Microbiol 10:502-508, 2002.

72. T Kitazume, A Tanaka, N Takaya, A Nakamura, S Matsuyama, T Suzuki, H Shoun. Kinetic analysis of hydroxylation of saturated fatty acids by recombinant p450foxy produced by an escherichia coli expression system. Eur J Biochem 269:2075-2082, 2002.

73. T Kitazume, N Takaya, N Nakayama, H Shoun. Fusarium oxysporum fatty-acid subterminal hydroxylase (cyp505) is a membrane-bound eukaryotic counterpart of bacillus megaterium cytochrome p450bm3. J Biol Chem 275:39734-39740, 2000.

74. V Urlacher, RD Schmid. Biotransformations using prokaryotic p450 monooxygenases. Curr Opin Biotechnol 13:557-564, 2002.

75. O Lentz, QS Li, U Schwaneberg, S Lutz-Wahl, P Fischer, RD Schmid. Modification of the fatty acid specificity of cytochrome p450 bm-3 from bacillus megaterium by directed evolution: A validated assay. J Mol Cat B 15:123-133, 2001. 
76. QS Li, U Schwaneberg, M Fischer, J Schmitt, J Pleiss, S Lutz-Wahl, RD Schmid. Rational evolution of a medium chain-specific cytochrome p-450 bm-3 variant. Biochim Biophys Acta 1545:114-121, 2001.

77. TW Ost, CS Miles, J Murdoch, Y Cheung, GA Reid, SK Chapman, AW Munro. Rational re-design of the substrate binding site of flavocytochrome p450 bm3. FEBS Lett 486:173-177, 2000.

78. ET Farinas, U Schwaneberg, A Glieder, FH Arnold. Directed evolution of a cytochrome p450 monooxygenase for alkane oxidation. Adv Synth Catal 343:601-606, 2001.

79. CF Oliver, S Modi, MJ Sutcliffe, WU Pimrose, LY Lian, GC Roberts. A single mutation in cytochrome p450 bm-3 changes substrate orientation in a catalytic intermediate and the regioselectivity of hydroxylation. Biochemistry 36:1567-1572, 1997.

80. SE Graham-Lorence, G Truan, JA Peterson, JR Falck, S Wei, C Helvig, JH Capdevila. An active site substitution f87v, converts cytochrome p450 bm-3 into a regio- and stereoselective (14s, 15r)-arachidonic acid epoxygenase. J Biol Chem 262:801-810, 1997.

81. G Truan, MR Komandla, JR Falck, JA Peterson. P450bm-3: Absolute configuration of the primary metabolites of palmitic acid. Arch Biochem Biophys 366:192-198, 1999.

82. JH Capdevila, S Wei, C Helvig, JR Falck, Y Belosludtsev, G Truan, SE GrahamLorence, JA Peterson. The highly stereoselective oxidation of polyunsaturated fatty acids by cytochrome p450 bm-3. J Biol Chem 271:22663-22671, 1996.

83. PC Cirino, Y Tang, K Takahashi, DA Tirrell, FH Arnold. Global incorporation of norleucine in place of methionine in cytochrome p450 bm-3 heme domain increases peroxygenase activity. Biotechnol Bioeng 83:729-734, 2003. 
84. A Glieder, ET Farinas, FH Arnold. Laboratory evolution of a soluble, self-sufficient, highly active alkane hydroxylase. Nat Biotechnol 20:1135-1139, 2002.

85. GCK Roberts. The power of evolution: Accessing the synthetic potential of p450s. Chemistry \& Biology 6:269-272, 1999.

86. U Schwaneberg, C Schmidt-Dannert, J Schmitt, RD Schmid. A continuous spectrophotometric assay for p450 bm-3, a fatty acid hydroxylating enzyme, and its mutant f87a. Anal Biochem 269:359-366, 1999.

87. WH Schunck, E Kargel, B Gross, B Wiedmann, S Mauersberger, K Kopke, U Kiessling, M Strauss, M Gaestel, HG Muller. Molecular cloning and characterization of the primary structure of the alkane hydroxylating cytochrome p450 from the yeast candida maltosa. Biochem Biophys Res Commun 161:843-850, 1989.

88. M Ohkuma, S Muraoka, T Tanimoto, M Fujii, A Ohta, M Takagi. Cyp52 (cytochrome p450alk) multigene family in candida maltosa: Identification and characterization of eight members. DNA Cell Biol. 14:163-173, 1995.

89. K Lottermoser, WH Schunck, O Asperger. Cytochromes p450of the sophorose lipidproducing yeast candida apicola: Heterogeneity and polymerase chain reactionmediated cloning of two genes. Yeast 12:565-575, 1996.

90. W Sghezzi, C Meili, R Ruffiner, R Kuenzi, D Sanglard, A Fiechter. Identification and characterization of additional members of the cytochrome p450 multigene family cyp52 of candida tropicalis. DNA Cell Biol 11:767-780, 1992.

91. U Scheller, T Zimmer, D Becher, F Schauer, WH Schunck. Oxygenation cascade in conversion of n-alkanes to $\alpha, \omega$-dioic acids catalyzed by cytochrome p450 52a3. J Biol Chem 273:32528-32534, 1998.

92. TL Rohrer ,SK Picataggio. Targeted integrative transformation of candida tropicalis by electroporation. Appl Microbiol Biotechnol 36:650-654, 1992. 
93. S Picataggio, T Rohrer, K Deanda, D Lanning, R Reynolds, J Mielenz, LD Eirich. Metabolic engineering of candida tropicalis for the production of long-chain dicarboxylic acids. Biotechnology (N Y) 10:894-898, 1992.

94. DL Craft, KM Madduri, M Eshoo, CR Wilson. Identification and characterization of the cyp52 family of candida tropicalis atcc 20336, important for the conversion of fatty acids and alkanes to alpha,omega-dicarboxylic acids. Appl Environ Microbiol 69:5983-5991, 2003.

95. FM Dickinson, C Wadforth. Purification and some properties of alcohol oxidase from alkane grown candida tropicalis. Biochem J 282:325-331, 1992.

96. T Zimmer, T Iida, WH Schunck, Y Yoshida, A Ohta, M Takagi. Relation between evolutionary distance and enzymatic properties among the members of the cyp52a subfamily of candida maltosa. Biochem Biophys Res Commun 251:244-247, 1998.

97. AE Simpson. The cytochrome p450 4 (cyp4) family. Gen Pharmacol 28:351-359, 1997.

98. S Rendic, FJ Di Carlo. Human cytochrome p450 enzymes: A status report summarizing their reactions, substrates, inducers and inhibitors. Drug Metab Rev 29:413-580, 1997.

99. MB Fisher, YM Zheng, AE Rettie. Positional specificity of rabbit cyp4b1 for $\omega-1$ hydroxylation of short-medium chain and hydrocarbons. Biochem Biophys Res Commun 248:352-355, 1998.

100. PP Tamburini, HA Masson, SK Bains, RJ Makowski, B Morris, GG Gibson. Multiple forms of hepatic cytochrome p450. Purification, characterisation and comparison of a novel clofibrate-induced isozyme. Eur J Biochem 139:235-246, 1984.

101. CW Fisher, MS Shet, DL Caudle, CA Martin-Wixtrom, RW Estabrook. High-level epression in escherichia coli of enzymatically active fusion proteins containing the 
domains of mammalian cytochromes p450. Proc Natl Acad Sci U S A 89:1081710821, 1992.

102. CS Chaurasia, MA Altermann, P Lu, RP Hanzlik. Biochemical characterization of lauric acid w-hydroxylationby a cyp4a1/nadph-cytochrome p450 reductase fusion protein. Arch Biochem Biophys 317:161-169, 1995.

103. U Hoch, Z Zhang, DL Kroetz, PR Ortiz de Montellano. Structural determination of the substrate specificities and regioselectivities of the rat and human fatty acid whydroxylases. Arch Biochem Biophys 373:63-71, 2000.

104. U Hoch, JR Falck, PRO Ortiz de Montellano. Molecular basis for the $\omega-$ regiospecificity of the cyp4a2 and cyp4a3 fatty acid hydroxylases. J Biol Chem 275:26952-26958, 2000.

105. MA Altermann, CS Chaurasia, P Lu, JP Hardwick, RP Hanzlik. Fatty acid discrimination and w-hydroxylation by cytochrome p450 4a1 and a cytochrome p4504a1/nadph-p450 reductase fusion protein. Arch Biochem Biophys 320:289-296, 1995.

106. BG Fox, Catalysis by non-heme iron, in Comprehensive Biological Catalysis, $\mathrm{M}$ Sinott, Editor. 1997, Academic: London. pp 261-348.

107. Y Lindqvist, WJ Huang, G Schneider, J Shanklin. Crystal structure of a $\delta^{9}$ stearoylacyl carrier protein desaturase from castor seed and its relationship to other diiron proteins. EMBO J 15:4081-4092, 1996.

108. N Elango, R Radhakrishnan, WA Froland, BJ Wallar, CA Earhart, JD Lipscomb, DH Ohlendorf. Crystal structure of the hydroxylase component of methane monooxygenase from methylosinus trichosporium ob3b. Protein Sci 6:556-568, 1997.

109. P Nordlund, H Eklund. Structure and function of the escherichia coli ribonucleotide reductase protein r2. J Mol Biol 232:123-164, 1993. 
110. BJ Wallar, JD Lipscomb. Dioxygen activation by enzymes containing binuclear nonheme iron clusters. Chem Rev 96:2625-2657, 1996.

111. DJJ Kurtz. Structural similarity and functional diversity in diiron-oxo proteins. JBIC 2:159-167, 1997.

112. LJ Shu, JC Nesheim, K Kauffmann, E Münck, JD Lipscomb, L Que. An fe ${ }_{2}{ }^{\mathrm{iv}} \mathrm{O}_{2}$ diamond core structure for the key intermediate q of methane monooxygenase. Science 275:515-518, 1997.

113. EJ McKenna, MJ Coon. Enzymatic $\omega$-oxidation. Iv. Purification and properties of the $\omega$-hydroxylase from pseudomonas oleovorans. J Biol Chem 245:3882-3889, 1970.

114. P Broun, J Shanklin, E Whittle, C Somerville. Catalytic plasticity of fatty acid modification enzymes underlying chemical diversity of plant lipids. Science 282:1315-1317, 1998.

115. S Stymne, A Green, S Singh, M Lenman. Genes for fatty acid d12-epoxygenase of fatty acid epoxide-containing plants and the development of useful producers of fatty acid epoxides. PCT Int. Appl.:150 pp., 1998.

116. WD Hitz. Fatty acid modifying enzymes from developing seeds of vernonia galamenensis and fatty acid desaturase gene DNA sequences, U.S. (E. I. Du Pont De Nemours and Company, USA). US. 21 pp., 1998.

117. EB Cahoon. Cloning and sequence of euphorbia lagascae cytochrome p 450 associated with the synthesis of d12-epoxy fatty acids in plants and construction of chimeric gene for production of d12-epoxy fatty acids, U.S. Pat. Appl. Publ. (USA). US. 30 pp., Cont. of U.S. Ser. No. 219,833., 2003.

118. E Hornung, S Rosahl, H Kühn, I Feussner. Creating lipoxygenases with new positional specificities by site-directed mutagenesis. Biochem Soc Trans 28:825-826, 2000. 
119. M Lee, M Lenman, A Banas, M Bafor, S Singh, M Schweizer, R Nilsson, C Liljenberg, A Dahlqvist, PO Gummeson, S Sjodahl, A Green, S Stymne. Identification of non-heme diiron proteins that catalyze triple bond and epoxy group formation. Science 280:915-918, 1998.

120. M Smith, H Moon, L Kunst. Production of hydroxy fatty acids in the seeds of arabidopsis thaliana. Biochem Soc Trans 28:947-950, 2000.

121. N Tijet, F Pinot, I Benveniste, BR Le, C Helvig, Y Batard, F Cabello-Huartado, D Werck-Reichhart, J-P Salaun, F Durst. Plant cytochrome p450-dependent fatty acid hydroxylase genes and their expression in yeast for manufacture of hydroxylated fatty acids, PCT Int. Appl. (The Centre National de Recherche Scientifique, Fr.). WO. 157 pp., 1999.

122. JB Ohlrogge. Design of new plant products: Engineering of fatty acid metabolism. Plant Physiol 104:821-826, 1994.

123. D Fabritius, HJ Schafer, A Steinbuchel. Biotransformation of linoleic acid with the candida tropicalis m25 mutant. Appl Microbiol Biotechnol 48:83-87, 1997.

124. EJ Corey, W-G Su, MB Cleaver. A simple and efficient synthesis of $(7 e, 9 e, 11 z, 13 e)-$ $(5 s, 6 r, 15 s)$-trihydroxyeicosatetraenoic acid (6r-lipoxin a). Tetrahedron Lett 30:41814184, 1989.

125. D Martini, G Iacazio, D Ferrand, G Buono, C Triantaphylides. Optimization of large scale preparation of 13(s)-hydroperoxy-9z,11e-octadecadienoic acid using soybean lipoxygenase.Application to the chemoenzymatic synthesis of $(+)$-coriolic acid. Biocatalysis 11:47-63, 1994.

126. D Martini, G Buono, G Iacazio. Regiocontrol of soybean lipoxygenase oxygenation. Application to the chemoenzymatic synthesis of methyl 15(s)-hete and methyl 5(s),15(s)-dihete. J Org Chem 61:9062-9064, 1996. 
127. D Martini, G Buono, J-L Montillet, G Iacazio. Chemo-enzymatic synthesis of methyl9(s)-hode (dimorphecolic acid methyl ester) and methyl-9(s)-hote catalysed by barley seed lipoxygenase. Tetrahedron: Asymmetry 7:1489-1492, 1996.

128. AF Hsu, E Wu, S Shen, TA Foglia, K Jones. Immobilized lipoxygenase in a packedbed column bioreactor: Continuous oxygenation of linoleic acid. Biotechnol Appl Biochem 30 ( Pt 3):245-250, 1999.

129. A Weiss, U Schoerken, V Candar, Y Eryasa, M Wunderlich, N Buyukuslu, C Beverungen. Process for the enzymic generation and recovery of fatty acid hydroperoxides, Eur. Pat. Appl. (Cognis Deutschland GmbH \& Co. K.-G., Germany). EP. 22 pp., 2003.

130. F Björkling, SE Godtfredsen, O Kirk. Lipase-mediated formation of peroxy carboxylic acids used in catalytic epoxidation of alkenes. J Chem Soc, Chem Commun:13011303, 1990.

131. S Warwel, MR Klaas. Chemoenzymic epoxidation of unsaturated carboxylic acids. J Mol Cat B: Enzymatic 1:29-35, 1995.

132. M Rüsch gen. Klaas, S Warwel. Enzymic preparation of peroxy-, epoxy- and peroxyepoxy fatty acids. Oils-Fats-Lipids 1995, Proceedings of the World Congress of the International Society for Fat Research, 21st, The Hague, Oct. 1-6, 1995 3:469-471, 1996.

133. M Rüsch gen Klaas, S Warwel, Lipase-catalyzed peroxy fatty acid generation and lipid oxidation, In: Enzymes in Lipid Modification, UT Bornscheuer, Editor. 2000, VCH: weinheim, New York. pp 116-127.

134. M Hamberg, G Hamberg. Arch Biochem Biophys 283:409-, 1990.

135. GJ Piazza, A Nunez, TA Foglia. Epoxidation of fatty acids, fatty methyl esters, and alkenes by immobilized oat seed peroxygenase. J Mol Cat B: Enzymatic 21:143-151, 2003. 
136. I Matsunaga, T Sumimoto, E Kusunose, K Ichihara. Phytanic acid a-hydroxylation by bacterial cytochrome p450. Lipids 33:1213-1216, 1998.

137. I Matsunaga, T Sumimoto, A Ueda, E Kusunose, K Ichihara. Fatty acid-specific, regiospecific, and stereospecific hydroxylation by cytochrome p450 (cyp152b1) from sphingomonas paucimobilis: Substrate structure required for a-hydroxylation. Lipids 35:365-371, 2000.

138. I Matsunaga, A Ueda, N Fujiwara, T Sumimoto, K Ichihara. Characterization of the ybdt gene product of bacillus subtilis: Novel fatty acid b-hydroxylating cytochrome p450. Lipids 34:841-846, 1999.

139. PC Cirino, FH Arnold. A self-sufficient peroxide-driven hydroxylation biocatalyst. Angew Chem Int Ed Engl 42:3299-3301, 2003.

140. BD Fleming, Y Tian, SG Bell, LL Wong, V Urlacher, HA Hill. Redox properties of cytochrome p450bm3 measured by direct methods. Eur J Biochem 270:4082-4088, 2003.

141. J Kazlauskaite, ACG Westlake, L-L Wong, HAO Hill. Direct electrochemistry of of cytochrome p450cam. Chem Commun 18:2189-2190, 1996.

142. KM Faulkner, MS Shet, CW Fisher, RW Estabrook. Electrocatalytically driven $\omega$ hydroxylation of fatty acids using cytochrome p450 4a1. Proc Natl Acad Sci U S A 92:7705-7709, 1995.

143. F Hollmann, PC Lin, B Witholt, A Schmid. Stereospecific biocatalytic epoxidation: The first example of direct regeneration of a fad-dependent monooxygenase for catalysis. J Am Chem Soc 125:8209-8217, 2003.

144. U Schwaneberg, D Appel, J Schmitt, RD Schmid. P450 in biotechnology: Zinc driven omega-hydroxylation of p-nitrophenoxydodecanoic acid using p450 bm-3 f87a as a catalyst. J Biotechnol 84:249-257, 2000. 
145. B Hauer, RD Schmid, U Schwaneberg. Electron donor system for redox enzymes and its use for preparation of hydroxylated fatty acids, PCT Int. Appl. (BASF

Aktiengesellschaft, Germany). WO. 94 pp., 2001.

146. P Fernandez-Salguero, C Gutierrez-Merino, AW Bunch. Effect of immobilization on the activity of rat hepatic microsomal cytochrome p450 enzymes. Enzyme Microb Technol 15:100-104, 1993.

147. F Hollmann, B Witholt, A Schmid. [cp*rh(bpy)(h2o)]2+: A versatile tool for efficient and non-enzymatic regeneration of nicotinamide and flavin coenzymes. J Mol Cat B 791:1-10, 2002.

148. VI Tishkov, AG Galkin, VV Fedorchuk, PA Savitsky, AM Rojkova, H Gieren, MR Kula. Pilot scale production and isolation of recombinant nad+- and nadp+-specific formate dehydrogenases. Biotechnol Bioeng 64:187-193, 1999.

149. S Maurer, V Urlacher, H Schulze, RD Schmid. Immobilisation of p450 bm-3 and an nadp+ cofactor recycling system: Towards a technical application of heme-containing monooxygenases in fine chemical synthesis. Adv Synth Catal 345:802-810, 2003. 